History of Resistance Welding Oxide Dispersion Strengthened Cladding and other High Temperature Materials at Center for Advanced Energy Studies

Larry Zirker Nathan Jerred Indrajit Charit James Cole

March 2012

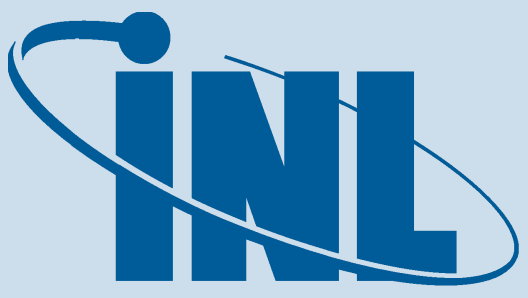

Idaho National Laboratory 


\section{DISCLAIMER}

This information was prepared as an account of work sponsored by an agency of the U.S. Government. Neither the U.S. Government nor any agency thereof, nor any of their employees, makes any warranty, expressed or implied, or assumes any legal liability or responsibility for the accuracy, completeness, or usefulness, of any information, apparatus, product, or process disclosed, or represents that its use would not infringe privately owned rights. References herein to any specific commercial product, process, or service by trade name, trade mark, manufacturer, or otherwise, does not necessarily constitute or imply its endorsement, recommendation, or favoring by the U.S. Government or any agency thereof. The views and opinions of authors expressed herein do not necessarily state or reflect those of the U.S. Government or any agency thereof. 


\title{
History of Resistance Welding Oxide Dispersion Strengthened Cladding and other High Temperature Materials at the Center for Advanced Energy Studies
}

\author{
Larry Zirker, INL \\ Nathan Jerred, University of Idaho \\ Dr. Indrajit Charit, University of Idaho \\ James Cole, INL
}

March 2012

Prepared for the

U.S. Department of Energy

Office of Nuclear Energy

Under DOE Idaho Operations Office

Contract DE-AC07-05ID14517 



\begin{abstract}
Research proposal 08-1079, “A Comparative Study of Welded ODS Cladding Materials for AFCI/GNEP," was funded in 2008 under an Advanced Fuel Cycle Initiative (AFCI) Research and Development Funding Opportunity, number DE-PS07-08ID14906. The proposal sought to conduct research on joining oxide dispersion strengthened (ODS) tubing material to a solid end plug. Project objectives included the following:
\end{abstract}

- Procure and install a new resistance welding system in the Center for Advanced Energy Studies (CAES) in Idaho Falls, Idaho

- Conduct fundamental joining research

- Support the university project team with welded samples

- Find optimum joining parameters for creating metallurgical bonding between the cladding and end plug materials

- Disseminate research results via conference proceedings, journal papers, and reports.

A summary of the scientific and technical progress achieved during the project, which ran from 2008 to 2011 , is as follows.

- Purchased a new resistance welding system from Centerline LTD (a manufacturer of resistance welding systems in Windsor, Ontario, Canada) in 2008. The welding system included a Transgun (CLTG-9636-15); soft touch ram; and $80 \mathrm{KVA}, 460 \mathrm{~V}$ transformer all mounted on a work table with wheels. Other equipment included a Tip force gauge (90061AADA), Medar weld controller, and a Miyachi weld checker, model MM-122A-00-01.

- Installed and operationally deployed the resistance welding system in the CAES facility in Idaho Falls, Idaho

- Wrote the operational test plan and CAES facility safety documents

- Successfully joined the following materials

- ODS alloys with yttria based particles

- MA 957 an Iron based ODS alloy.

- MA 754 an Nickel based ODS alloy

- MA 956 an Iron based ODS alloy

- Ferritic-Martensitic alloys

- HT-9

- Refractory metals

- Pure Tungsten

- WC-Co

- Obtained excellent metallurgical bonding of ODS materials

- Designed and installed improved electrode fixtures with collets to achieve consistent tube welds. The clamshell fixtures on the older system gave uneven heating between the end plug and tube. The new collet fixtures solve this uneven heating. 
- Developed excellent working relationships between the project and CAES in providing stateof-the-art electronic metallurgical and microscopic examination of samples.

This page intentionally left blank. 


\section{Contents}

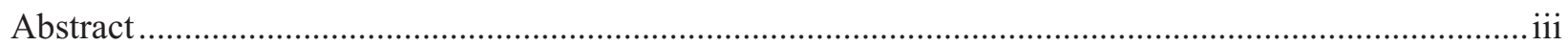

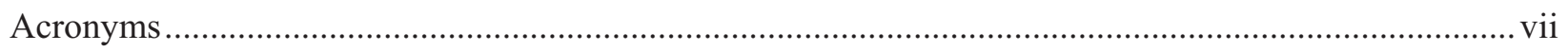

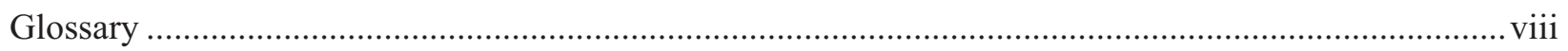

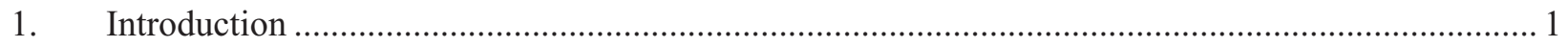

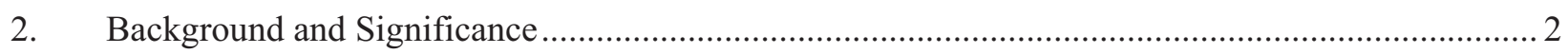

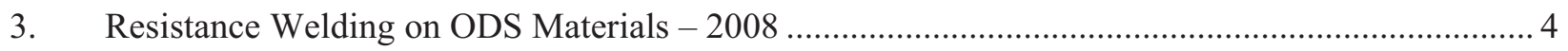

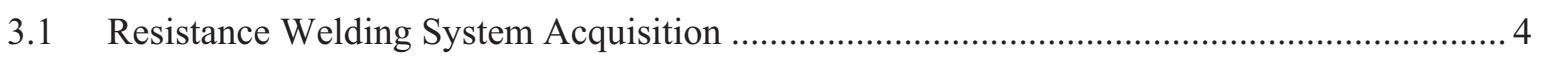

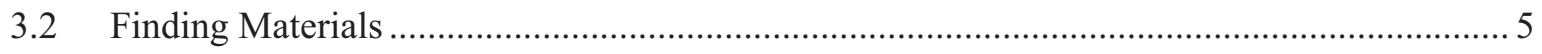

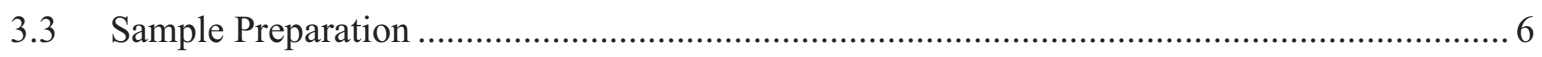

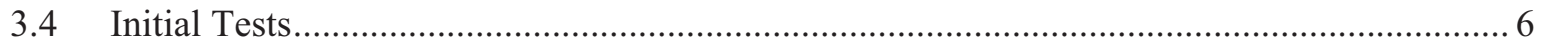

3.5 Resistance Welding in the CAES Facility ........................................................................ 7

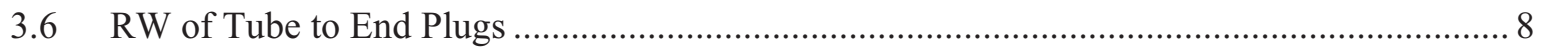

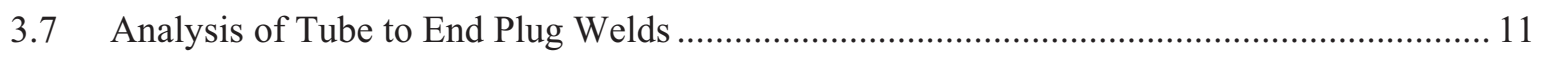

3.8 RW of Non-Tubular ODS Materials to Other Materials ................................................... 15

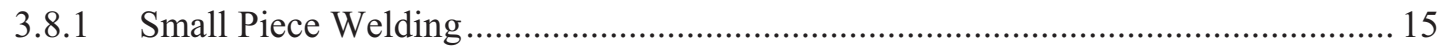

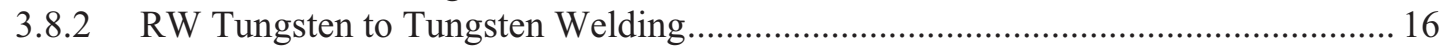

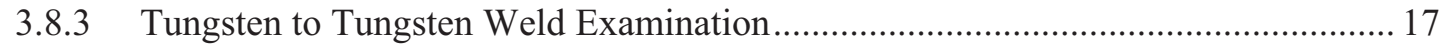

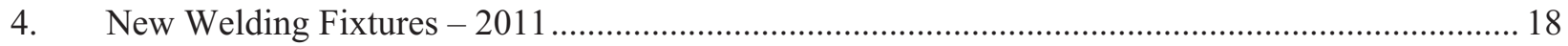

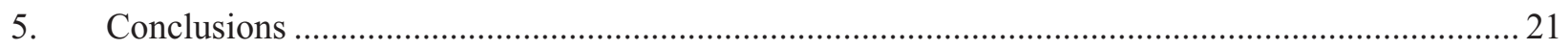

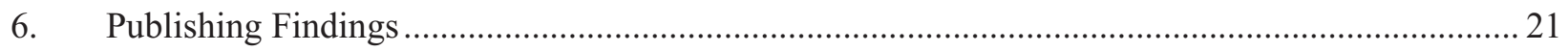

\section{Figures}

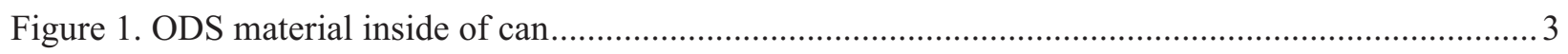

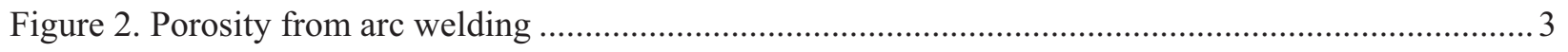

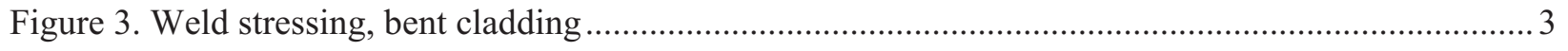

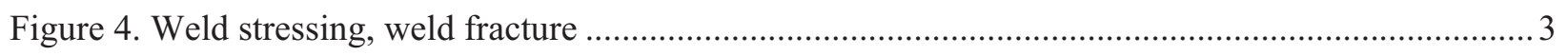

Figure 5. Graduate student setting up the UI RW system for welding at Centerline ................................. 5

Figure 6. Chemical compositions (wt\%) of the materials .......................................................................

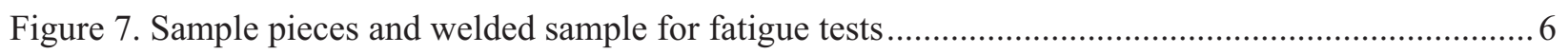

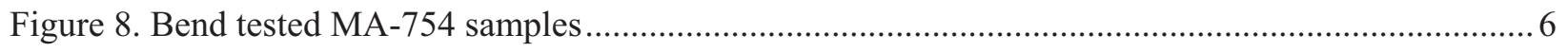

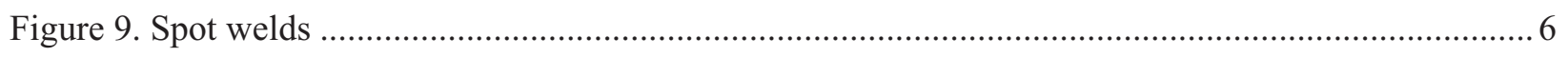

Figure 10. Spot welds that were too hot and where oxides created porosity, both samples ...................... 7

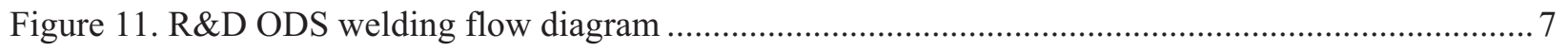

Figure 12. Nathan Jerred with pendent and laptop ….................................................................. 8 


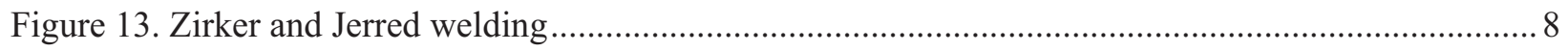

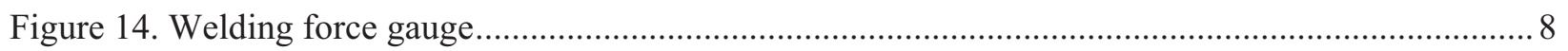

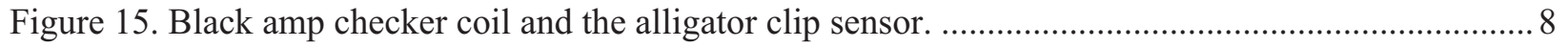

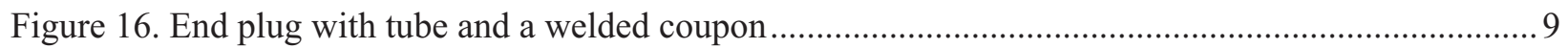

Figure 17. End plug and tube showing stick out before welding........................................................ 9

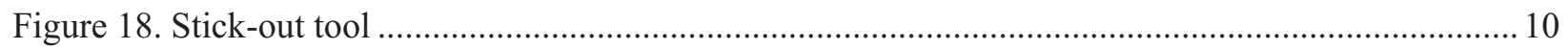

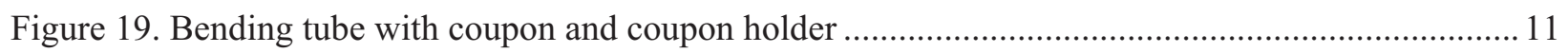

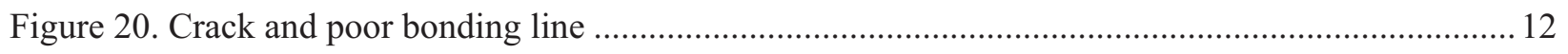

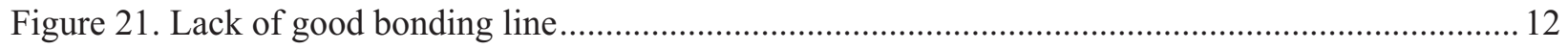

Figure 22. Severe lack of bonding and cracks at interface on both photographs.................................... 12

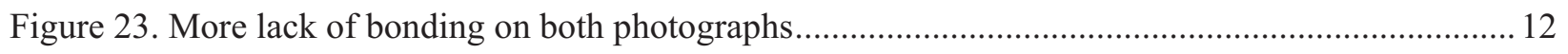

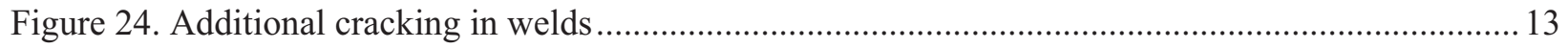

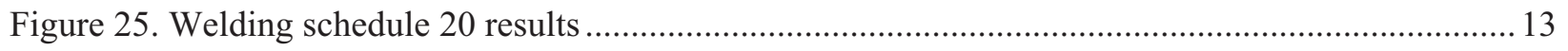

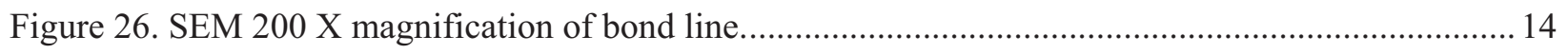

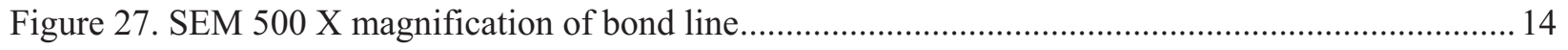

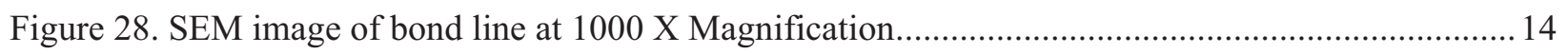

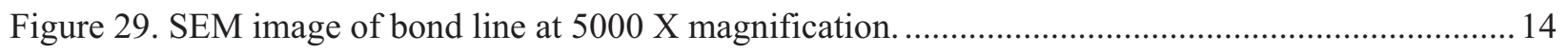

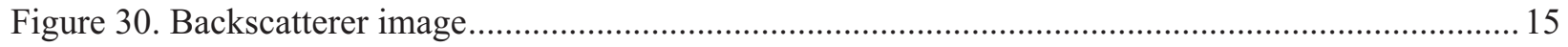

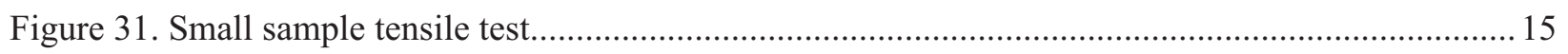

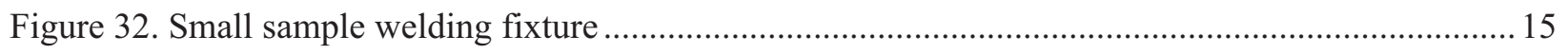

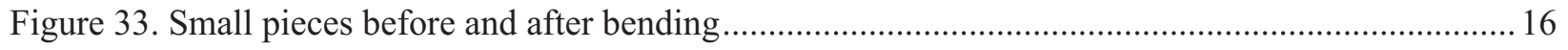

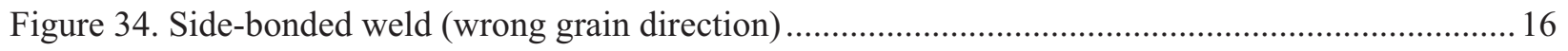

Figure 35. Polished sample but shows misalignment of pieces. ........................................................... 16

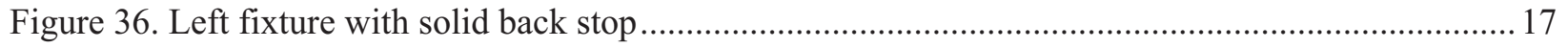

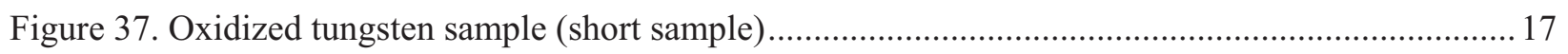

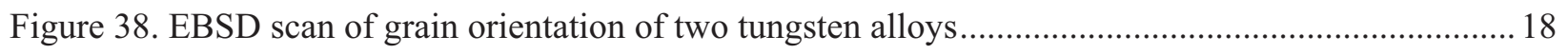

Figure 39. Uneven heating or tempering mark on half of end plug..................................................... 18

Figure 40. Arrow shows direct path of current — through the bottoms of both fixtures............................. 19

Figure 41. Difference between weld nugget of both sides of the same weld........................................... 19

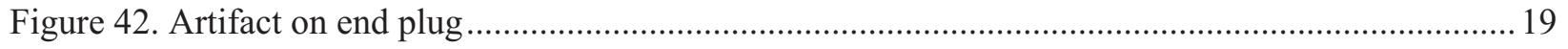

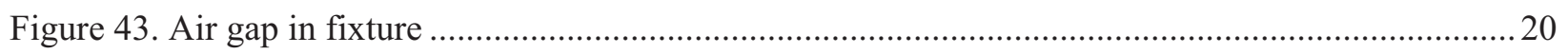

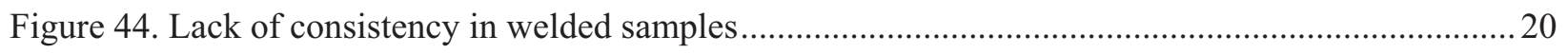

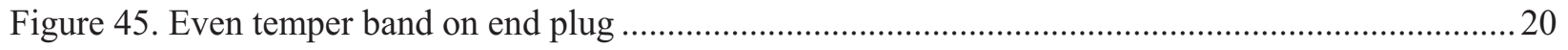

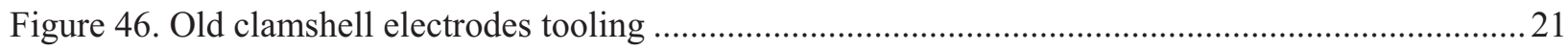

Figure 47. Collet electrode tooling with stiffener ............................................................................ 21

Figure 48. Nathan Jarred at the Idaho Space Grant Consortium Graduate Student Poster Session in 2010 


\section{Acronyms}

AFCI Advanced Fuel Cycle Initiative

CAES Center for Advanced Energy Studies

HT-9 Martensitic stainless steel used for end plugs on fuel elements

INL Idaho National Laboratory

LDRD Laboratory Directed Research and Development

ODS Oxide Dispersion Strengthened

PRW Pressure Resistance Welding

R\&D Research and Development

RBW Resistance Butt Welding

RW Resistance Welding

UI University of Idaho 


\section{Glossary}

Powder Metallurgy Powder metallurgy is the process of blending fine powdered materials, pressing them into a desired shape (compacting), and then heating the compressed material in a controlled atmosphere to bond the material (sintering). The powder metallurgy process generally consists of four basic steps: (1) powder manufacture, (2) powder blending, (3) compacting, and (4) sintering. [Wikipedia]

Pressure Resistance Welding (PRW) and Resistance Butt Welding (RBW)

Solid State Bonding

Oxide Dispersion Strengthened (ODS) Tubing

Cladding or Jacket Material

End plugs
A resistance welding (RW) process for joining end-to-end positioned (round or tubular) work pieces. RW is a synergism between pressure or force applied to the work pieces, the amperage or heat applied between the work pieces, and time under the force and heat that creates the forge bonding between the two pieces. The PRW and the RBW processes are essentially the same for the ODS welding.

Solid state bonding is not fusion joining in that the faying surfaces are not melted together, typical of fusion bonding. The contact surfaces, under heat and pressure, become forced together tight enough to allow the grains to grow together, and the interface surfaces disappear.

The ODS tubing used for this project was a ferritic stainless steel formed using powder metallurgy with a nano-scale metal oxide powder (Yttrium) in the alloying mixture. ODS tubing has shown to possess high temperature and high strength properties, and demonstrates longer jacket or fuel element cladding life in a reactor core.

Cladding or jacket material is the tube that holds or encapsulates nuclear fuel in a reactor.

An end plug is a solid right cylinder of a stainless steel alloy welded to both ends of a jacket. The end plug both contains the fuel, but also provides an attachment point between the fuel element and the reactor core assembly. 


\title{
History of Resistance Welding Oxide Dispersion Strengthened Cladding and other High Temperature Materials at the Center for Advanced Energy Studies
}

\author{
1. Introduction
}

Research proposal 08-1079, “A Comparative Study of Welded ODS Cladding Materials for AFCI/GNEP," was funded in 2008 under an Advanced Fuel Cycle Initiative (AFCI) Research and Development (R\&D) Funding Opportunity, number DE-PS07-08ID14906. The proposal - written by a consortium of universities that includes Boise State University (BSU), University of Idaho (U of I), and North Carolina State University (NCSU) with the Idaho National Laboratory (INL) as a partner proposed to conduct research on joining oxide dispersion strengthen (ODS) tubing material to a solid end plug. Project objectives included the following:

- Procure and install a new resistance welding system in the Center for Advanced Energy Studies (CAES) in Idaho Falls, Idaho

- Conduct fundamental joining research

- Support the university project team with welded samples

- Find optimum joining parameters for creating metallurgical bonding between the cladding and end plug materials

- Disseminate research results via conference proceedings, journal papers and reports. follows:

A summary of the scientific and technical progress achieved during the life of the project is as

- Purchased a new resistance welding system from Centerline Windsor Ltd. of Windsor, Ontario, Canada (a manufacturer of resistance welding systems in the automotive industry) in 2008. The welding system included a Transgun (CLTG-9636-15); soft touch ram; and 80 KVA, $460 \mathrm{~V}$ transformer all mounted on a table with wheels. Other equipment included a Tip force gauge (90061-AADA), Medar weld controller, and a Miyachi weld checker, model MM-122A-00-01.

- Installed and operationally deployed the resistance welding system in the CAES facility in Idaho Falls, Idaho

- Wrote the operational test plan and CAES facility safety documents

- Successfully joined the following materials:

- ODS alloys with yttria based particles

- MA 957 an Iron based ODS alloy.

- MA 754 an Nickel based ODS alloy

- MA 956 an Iron based ODS alloy

- Ferritic-Martensitic (F/M) alloys

- HT-9

- Refractory metals

- Pure Tungsten 
- WC-Co

- Obtained excellent metallurgical bonding

- Designed and installed improved electrode fixtures with collets to achieve even resistance heating between the end plug and tubing materials, thus producing consistent welds

- Developed excellent working relationships between the project and CAES in providing stateof-the-art electronic metallurgical and microscopic examination of samples.

- Published multiple papers and posters, and one Master's degree thesis.

\section{Background and Significance}

Research literature shows a significant amount of effort devoted to determining the properties and understanding the behavior of ODS steel to define its use as a nuclear cladding material. A partial list of citations, several of which include sections relating to joining, appears in Appendix A.

Joining research at the INL began in 1991 and focused on using ODS welding using a variation of resistance welding (RW). This research produced two benchmark citations. The first was the 1991 conference report "Fabrication of Oxide Dispersion Strengthened Ferritic Clad Fuel Pins" [Zirker]. The second was the 2002 report "ODS Steel Clad MOX Fuel-Pin Fabrication and Irradiation Performance in EBR-II" [Bottcher], which detailed the post-irradiation examination (PIE) results of the ODS welded elements run in Experimental Breeder Reactor (EBR)-II. The complete text of both of these reports is included in Appendix B.

The initial work, conducted in 1991 as part of a U.S. Department of Energy (DOE)/Japan-PNC collaboration known as the Operational Reliability Testing Program, investigated the joining of two ODS alloys-INCO MA957 alloy and an alloy developed by the Power Reactor and Nuclear Fuel Development Corporation (PNC) in Japan. This work had three goals: (1) develop a fabrication technique or methodology to meet DOE-Argonne National Laboratory (ANL) specifications; (2) qualify the weld to a standard; and (3) design and fabricate the fuel-pin to DOE safety, engineering, and quality assurance specifications and requirements for EBR-II.

ODS alloys possess desirable, low-neutron swelling characteristics and high-temperature mechanical properties for longer life and higher temperatures of operation, which lead to lower power generation costs. These alloys achieve their elevated temperature strength and creep resistance from the finely dispersed yttrium based oxides. These materials are developed via a solid state mechanical alloying processing used in conjunction with hot isostatic pressing (HIP). Figure 1 shows a photograph of an ODS ingot; the outer carbon steel can or mold is evident in the photograph. Because of the oxide particles, the joining is limited to a solid state process. Fusion welding or arc welding processes are not possible on ODS materials because the oxide particles float in liquid metal and agglomerate on resolidification when melted. Figure 2 shows an example of the porosity when arc welded. The diameter of the large pore in Figure 2 is about 0.01 -inch. 


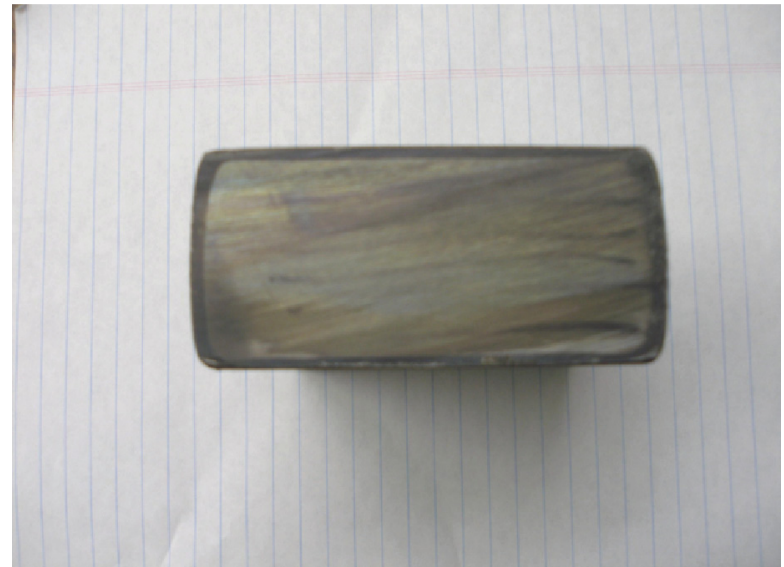

Figure 1. ODS material inside of can

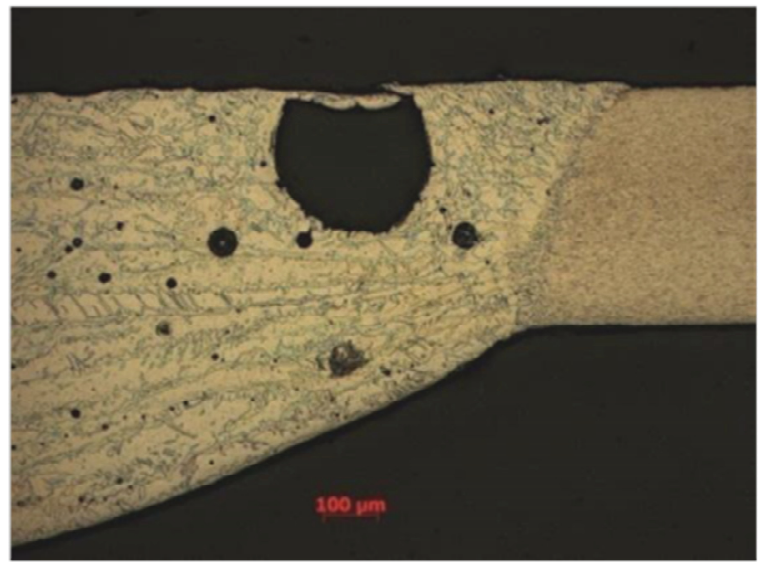

Figure 2. Porosity from arc welding

Several solid state welding processes were investigated for the project, but RW was selected because of the low equipment costs and effective joining. Centerline Windsor Ltd. offered their R\&D laboratory and research staff to help with the initial feasibility study investigation and developed a welding schedule for nuclear materials. Their facilities and systems were excellent and their staff highly knowledgeable. In just a few days, Centerline developed a welding procedure that successfully joined the MA957 ODS tubing to a martensitic, HT-9, alloy end plug. The success was measured via a traditional destructive bend test that stressed the weld. Essentially, the end plug was tightly secured in a vise and the tube was bent to stress the weld. If the weld strength was stronger than the tube, then the tube bent. An example of this test is shown in Figure 3 and Figure 4.

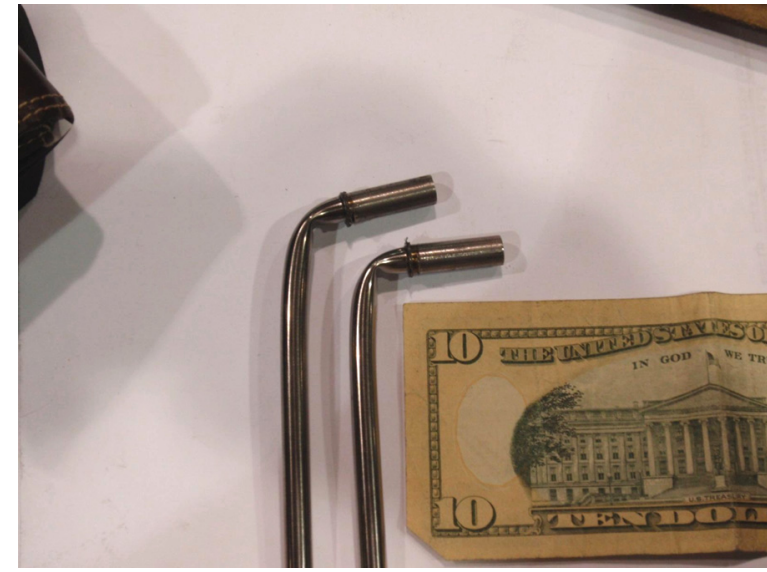

Figure 3. Weld stressing, bent cladding

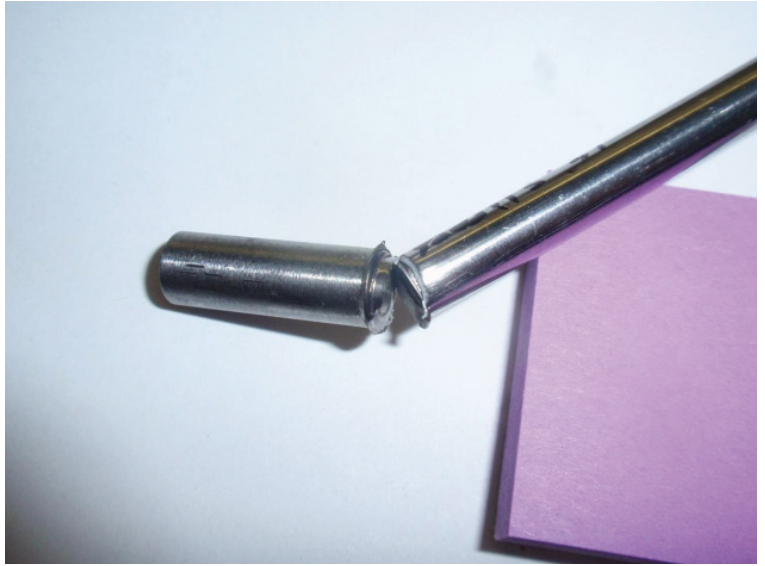

Figure 4. Weld stressing, weld fracture

After several iterations of welded samples using various welding parameters along with metallurgical analysis, excellent metallurgical bonds and procedure parameters were established. Two welding systems were eventually purchased from Centerline in 1991. One system used a C-frame configuration, and the other system deployed scissor type electrode arms. The C-frame system was used to weld the bottom endplugs onto cladding in a laboratory environment. The scissor arms system was used to extend into a glovebox through a glove port opening to conduct tube closure welding of irradiated fuel pins or elements. A report of the development of the welding systems and the welding effort is detailed in the 1991 Zirker report. A series of fuel elements was fabricated at the then Argonne National LaboratoryWest facility and subsequently placed into the EBR-II reactor. The 1991 Bottcher report details the results of the PIE and performance results. 
The significant effort conducted in 1991 and 1992 included:

- Purchased two RW systems for joining ODS tubing

- Developed a welding schedule to join ODS tubing

- Welded nuclear fuel elements for EBR-II

- Documented the joining effort and the performance of the fuel elements.

\section{Resistance Welding on ODS Materials - 2008}

In 2008, a consortium of universities -BSU, U of I, and NCSU - partnered with INL to conduct research on joining ODS materials using RW in the CAES facility. The technical approach of this R\&D effort included the following tasks:

- Acquiring the RW system

- Finding materials

- Preparing samples

- Conducting initial tests

- Setting up for welding in the CAES facility

- Conducting RW tube to end plug welds

- Analyzing RW tube to end plug welds

- Conducting RW of non-tubular ODS materials to other materials

- Conducting RW Tungsten to Tungsten welds

- Examining Tungsten to Tungsten welds

- Fabricating new welding fixtures

- Publishing Findings

\subsection{Resistance Welding System Acquisition}

The welding team acquired a new RW system identical to the system purchased in 1991, but with additional ancillary data acquisition systems. Centerline Windsor, LTD was contacted about the project and agreed to build another RW system. The design of the systems was generated and submitted to them for bid. Appendix C contains the estimate for bid from Centerline. As part of the purchase agreement, the welding system underwent verification and validation $(\mathrm{V} \& \mathrm{~V})$ testing before shipment of the system to CAES. Figure 5 shows a photograph of the welding system in the Centerline laboratory. 


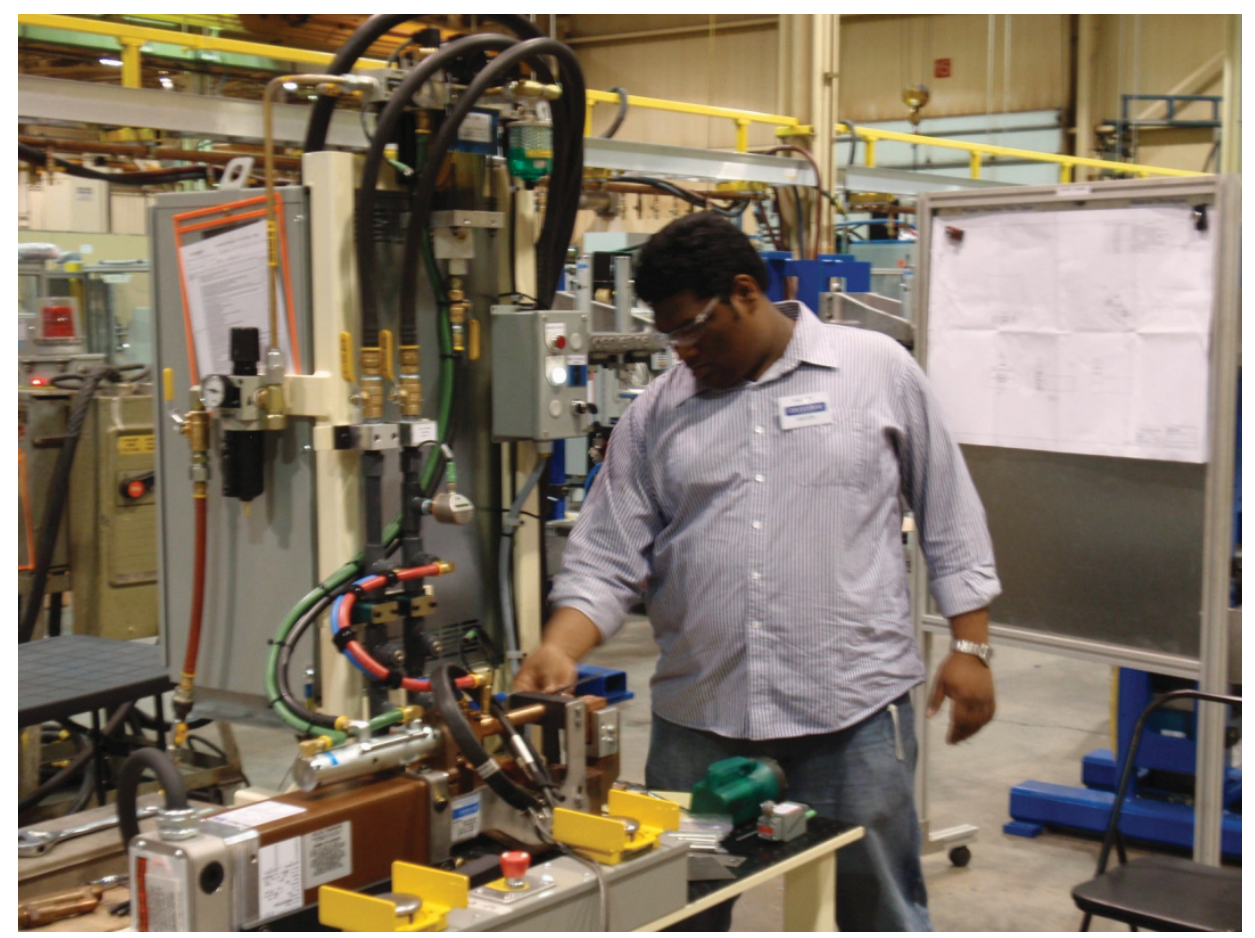

Figure 5. Graduate student setting up the UI RW system for welding at Centerline

\subsection{Finding Materials}

Part of the 2008 effort was to acquire ODS materials for the testing. Some materials were on-hand from earlier work, and other INL researchers had excess ODS stock and remnants from prior tests that were gifted to the project. The pieces included MA-956 (iron based ferritic alloy) and MA-754 (nickel based ferritic alloy). Also, researchers at the Materials and Fuels Complex (MFC) donated pieces of HT-9 and sections of MA-957 tubing for the tests. Error! Reference source not found. shows the alloying constituents of the various materials. A short length of 1-inch diameter MA-754 was also donated by a scientist from the Pacific Northwest National Laboratory. These pieces were sectioned and sent to the university teams so they could fabricate precise coupon pieces for weld testing. Appendix D details of coupon fabrication and coupon needs of each school.

Table 1. Chemical composition (wt $\%$ ) of the material

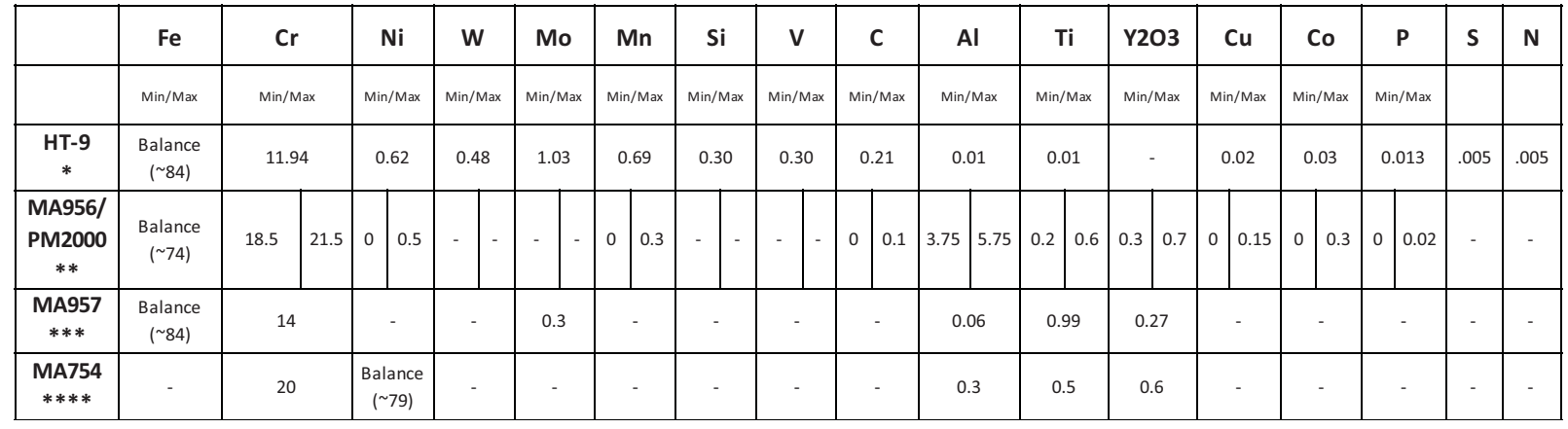




\subsection{Sample Preparation}

An early aspect of the work related to sample preparation. Large pieces of the HT-9, MA-957, MA754, MA 956, and Inconel 718 were sent to each partner university, and a sample preparation sheet was prepared detailing the size and number of samples. Because of the scarcity of material for the larger fatigue sample, some Inconel 718 pieces were fabricated to check out fixtures and develop a welding schedule before consuming the few ODS pieces.

\subsection{Initial Tests}

Because the researchers were anxious for some welded samples, Centerline agreed to conduct some preliminary welding of ODS tubing and other ODS materials at their facility following V\&V of the system. This preliminary welding provided welded samples of materials to the university teams for analysis, from which the universities developed a baseline of the weldability of the available ODS tubing material. Examples of these initial test samples are shown in Figure 6 through Figure 9. BSU also conducted some crack testing and other work on these initial samples. Appendix E contains reports of their work.
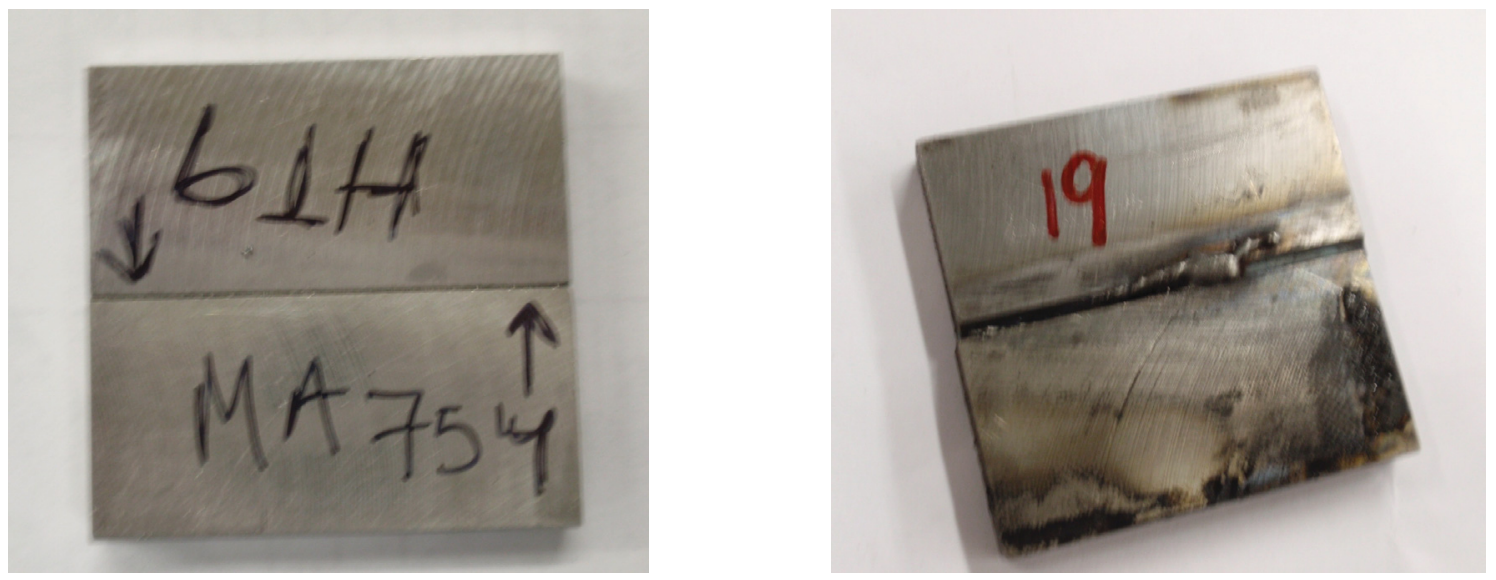

Figure 6. Sample pieces and welded sample for fatigue tests

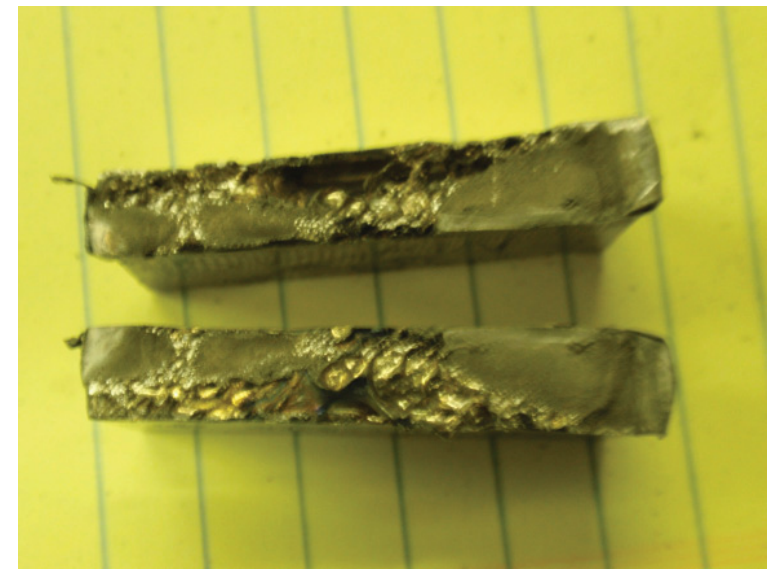

Figure 7. Bend tested MA-754 samples

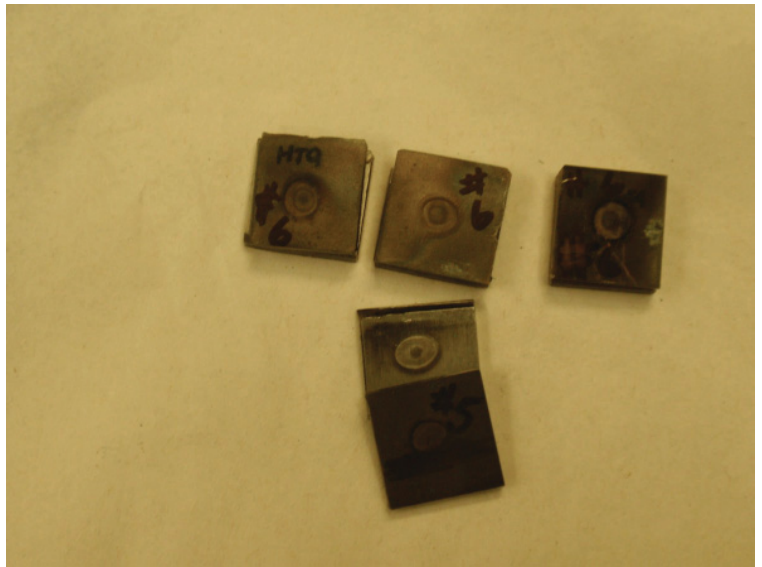

Figure 8. Spot welds 

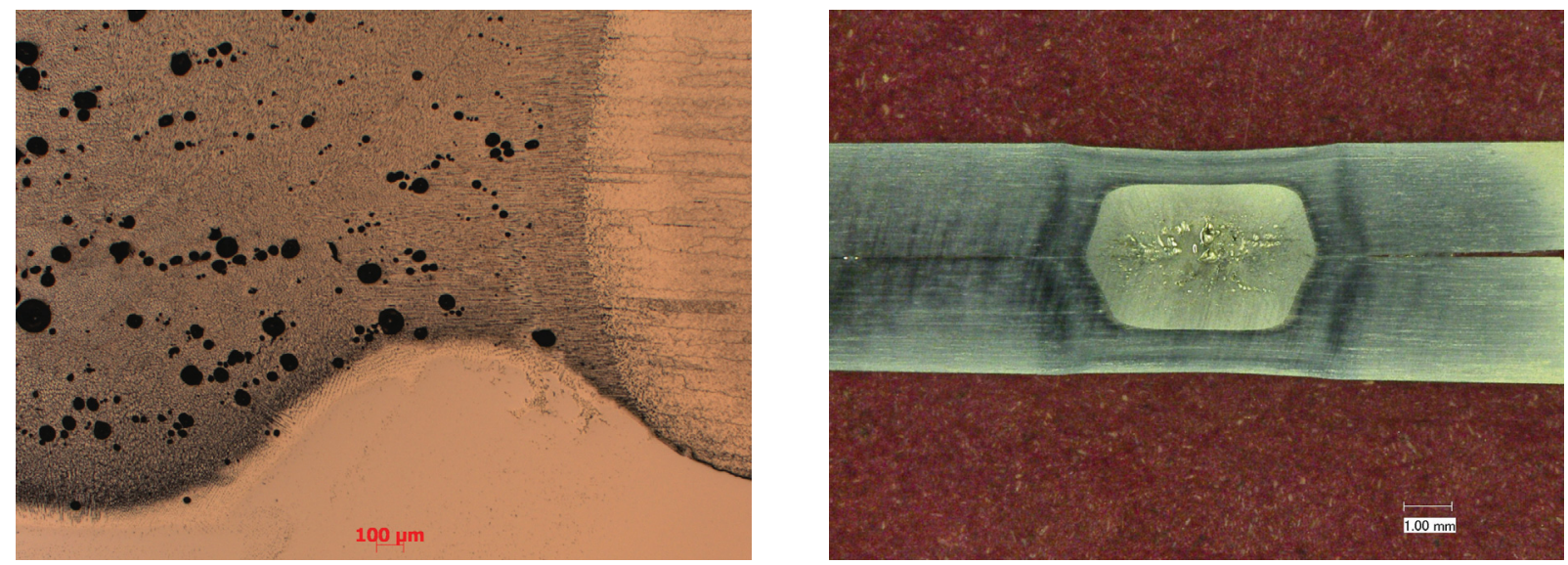

Figure 9. Spot welds that were too hot and where oxides created porosity, both samples

\subsection{Resistance Welding in the CAES Facility}

The RW welding system was set up in the CAES facility in the summer of 2008, and the research team wrote a welding plan and safety documents to conduct research in the Materials Laboratory. These documents are included in Appendix F. Figure 10 shows a flow diagram of the planned R\&D effort.

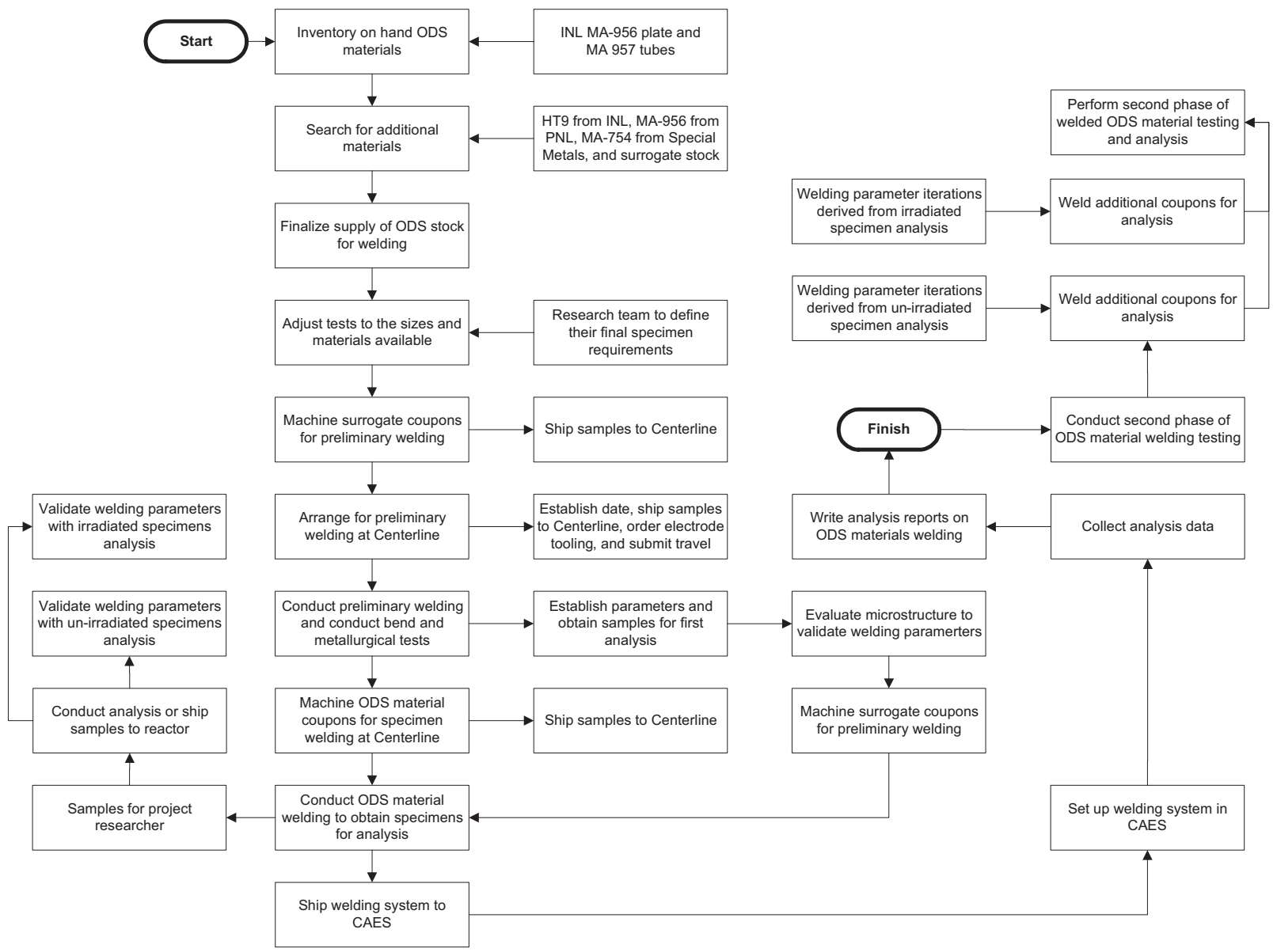

Figure 10. R\&D ODS welding flow diagram 


\subsection{RW of Tube to End Plugs}

Except for a few tubes welded at Centerline, all of the ODS tube to martensitic end plug welds were performed on the RW system in CAES. Essentially $100 \%$ of the welding was performed by U of I graduate student, Nathan Jerred. Nathan programmed the parameters into the laptop computer controlling the welding schedules, energized the 480 -volt system, operated the controls of the system, and collected the data acquisition records. Error! Reference source not found. shows Nathan at the controls. He was supported by Larry Zirker, an INL welding engineer. Zirker directly assisted the welding by aligning the coupon, setting up the data acquisition connections, taking the force reading, and remaining on-hand for most of the welding. Error! Reference source not found. shows the CAES welding team.

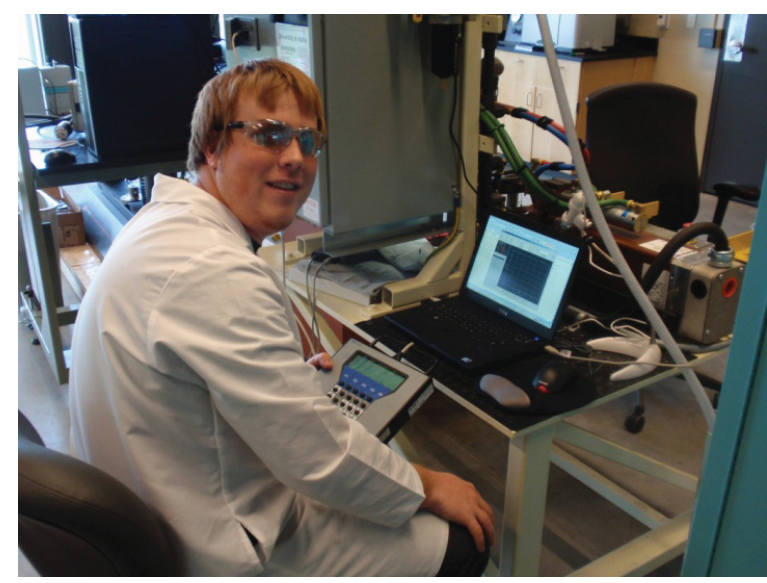

Figure 11. Nathan Jerred with pendent and laptop

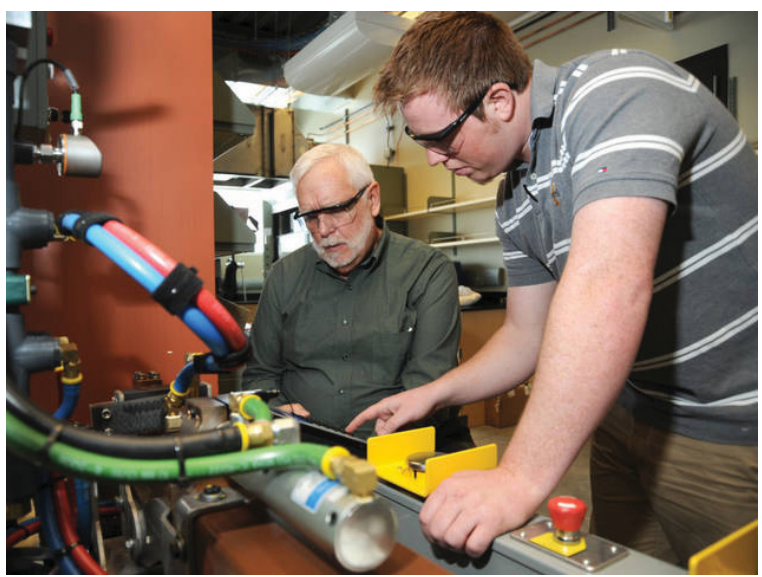

Figure 12. Zirker and Jerred welding

Before welding began on any day, the pressure was measured and set by inserting a welding force gauge between the fixtures and actuating the hydraulic ram to measure the force. The air regulators were then adjusted to achieve 1000 pounds of force between the fixtures. Figure 13 shows the calibrated welding force gauge.

The Joule heating principle $\left(\mathrm{H}=\mathrm{I}^{2} \mathrm{Rt}\right)$ provides the heat for welding. The amperes were measured using amp checker coil and sensor clip. Both the amp checker coil and sensor clip are shown in Figure 14; the amp checker is looped over the copper shaft containing the welding fixture.

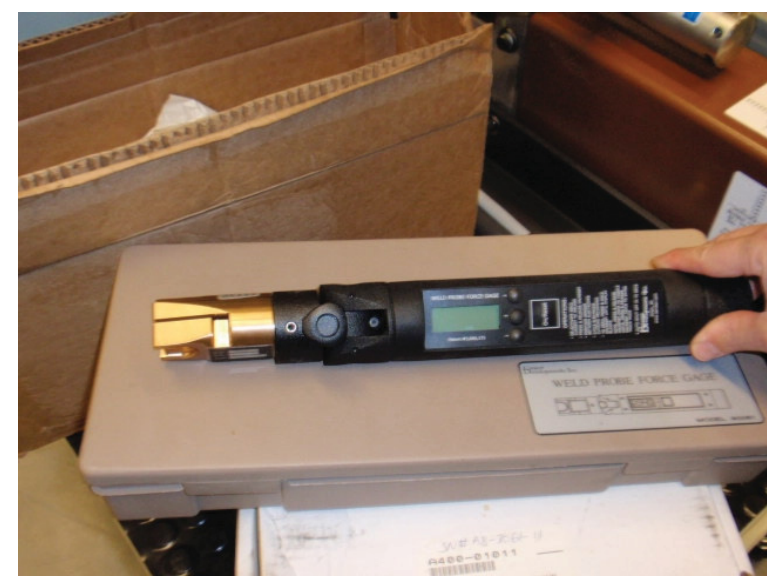

Figure 13. Welding force gauge

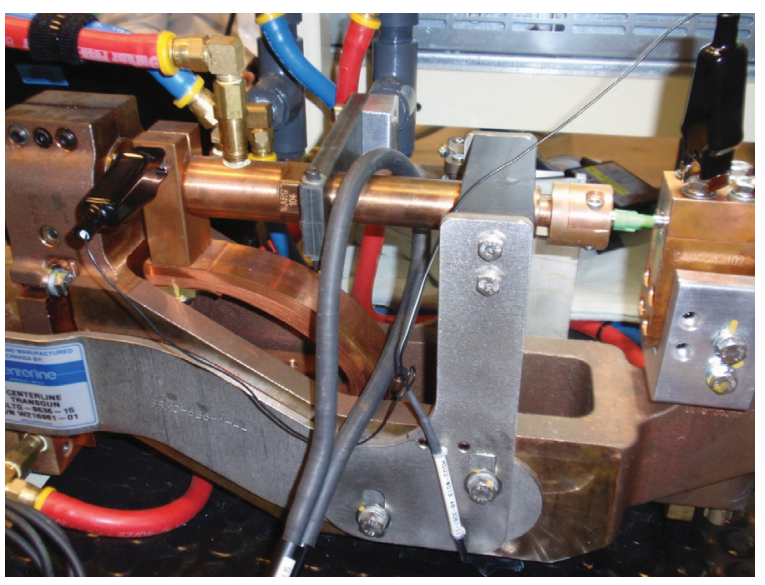

Figure 14. Black amp checker coil and the alligator clip sensor. 
The available ODS tubing consisted of remnants from some INCO MA-957 stock $(0.27$-inch diameter with 0.020 wall thickness) from the $1990 \mathrm{~s}$. These were typically machined to 7 -inches in length and after welding were machined or refaced for reuse. The end plugs were fabricated from 7/16-inch HT-9 rod stock that was machined down to 5/16-inch diameter. The end plugs were designed with a slight oversize on the diameter dimension to ensure that the weld would be complete even if the tube and end plug were not perfectly aligned. A photograph of the two welding coupon pieces and a welded coupon is shown in Figure 15.

Typically in RW, copper alloy electrodes squeeze the two metal pieces as a current is passed through the assembly to join a spot between the faying surfaces. In this case, copper fixtures were fabricated to hold the tube and end plug pieces. Essentially, the tube and end plugs became the electrodes and the faying surfaces between the tube and end plug were forged together. Figure 16 shows samples just prior to welding. As shown, both the tube and the end plug stick out from the fixture, allowing the ends of the pieces to heat up from the resistive heating caused by the current passing through the coupons. The high current density occurs at the tube interface due to the small surface area. The typical joining utilizes 10,000 amperes for 33 milliseconds. If the tube and end plug did not stick out, the current would just readily pass through the copper fixtures and no resistive heat would occur because the copper fixtures conduct the electricity so well. Consider a bread toaster with copper elements. No toast would be made because the element would not glow hot since the copper is such a good conductor of electricity without much resistive heating.

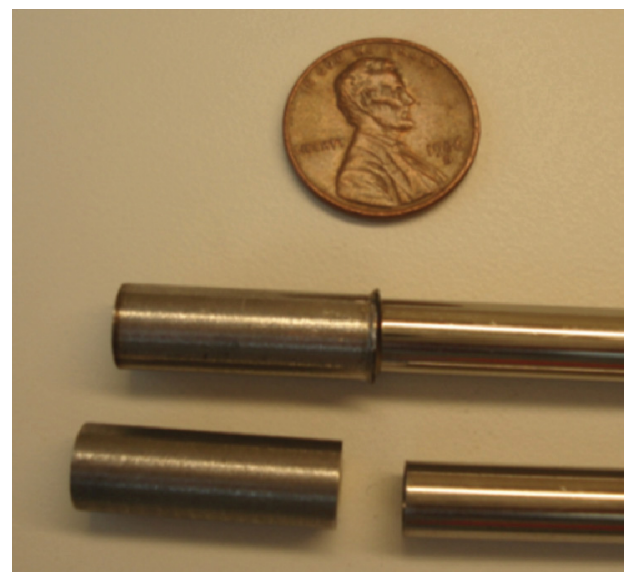

Figure 15. End plug with tube and a welded coupon

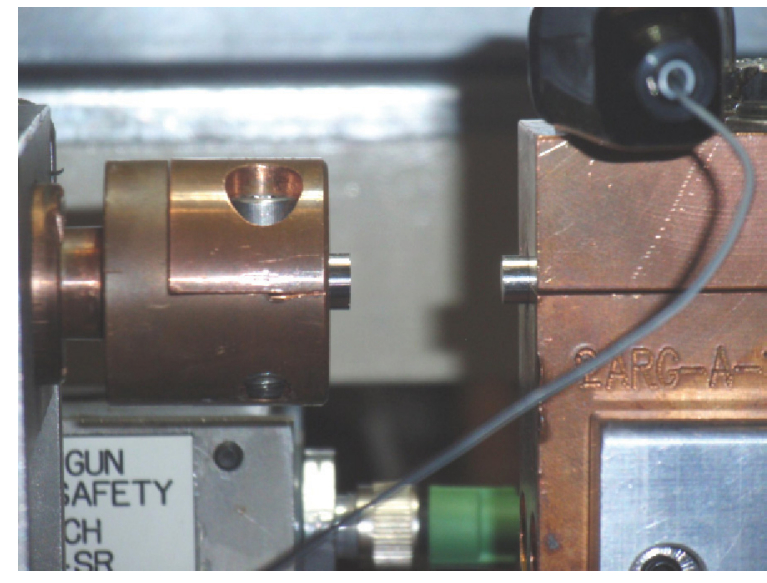

Figure 16. End plug and tube showing stick out before welding.

A "stick-out" tool was fabricated to facilitate consistent stick-out of the coupons without using a feeler gauge. The details of the tool are shown in Figure 17. 


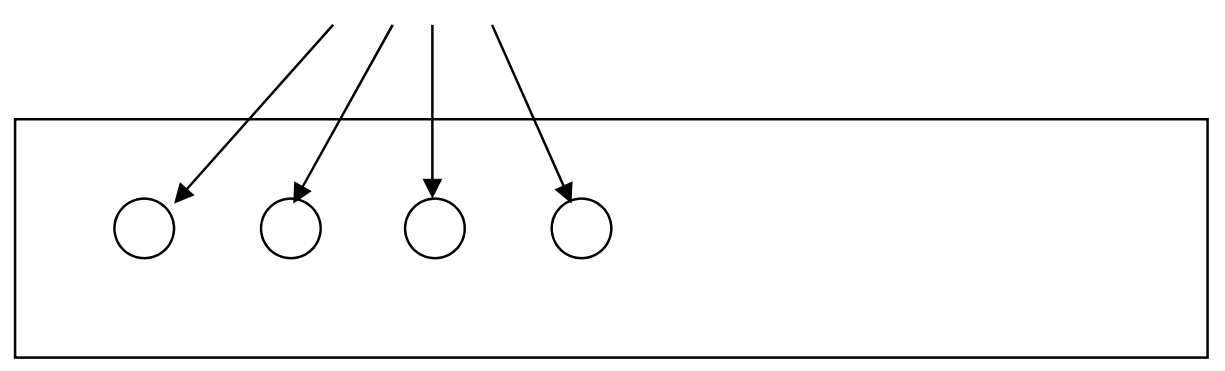

1 to 1.25 -inch wide

Hole Depth

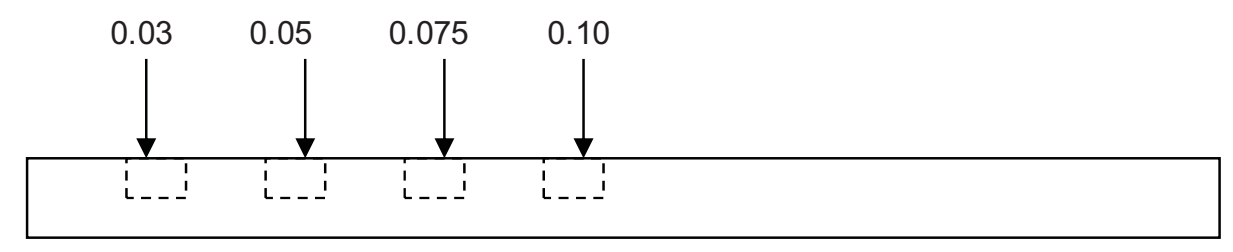

0.375 to 0.5 -inch thick

\section{5 to 7 inches long}

Figure 17. Stick-out tool

The welding parameters from the 1991 work were used as a starting point for the 2008 effort, but the welding was under powered and the weld would fail during testing. The common method of conducting a quick and easy RW quality or validation check is with a peal test wherein two pieces are welded together and then peeled apart. Welded samples are tightly secured in a vise and a 12-inch long tube with a slightly larger diameter than the sample is slipped over the sample so that the weld could be stressed with a bending force. If the weld quality is good, the tube bends, but if the bending stresses are greater than the strength of the weld, then the weld breaks or fails. Since the CAES laboratory didn't have a vise, a block was machined with a hole just larger than the end plug, and the block was held secure with the arbor press. The bending tube, bending block, and a welded sample are shown in Figure 18. 


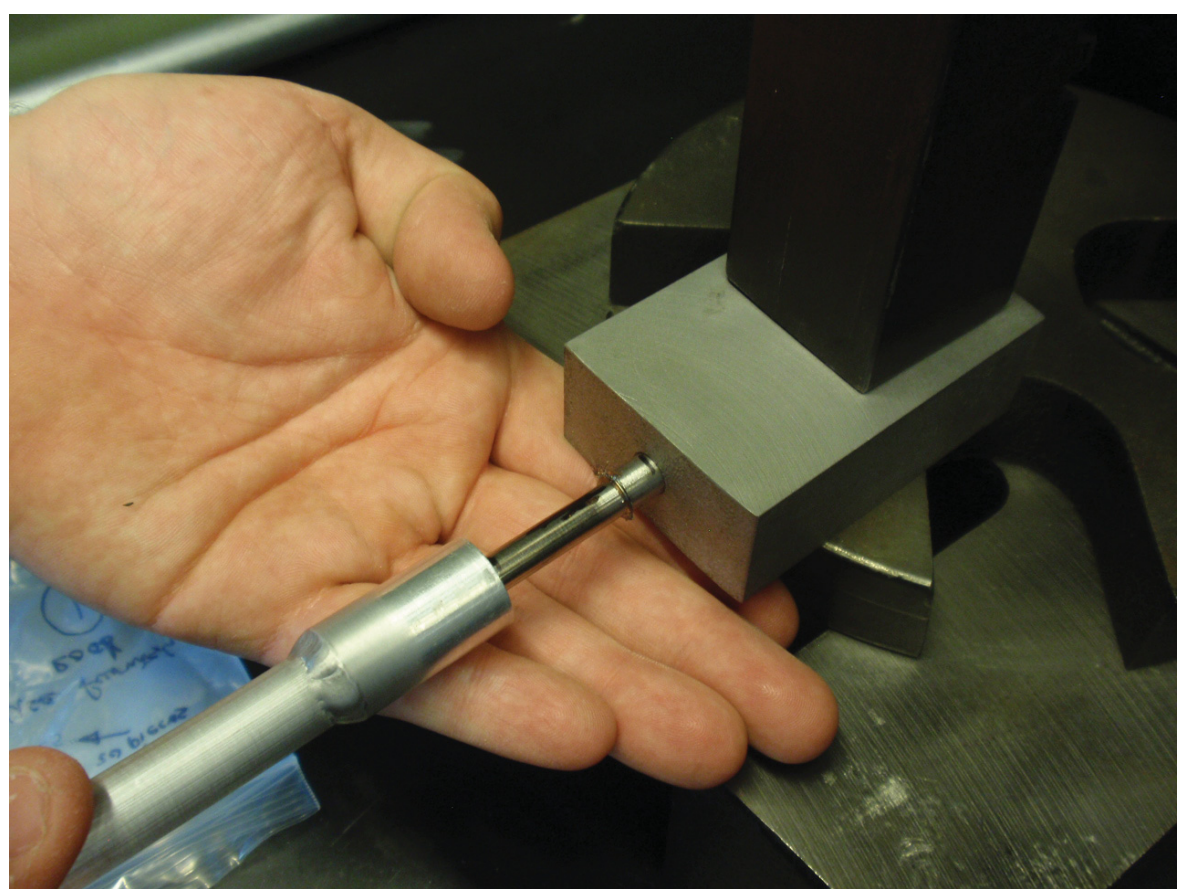

Figure 18. Bending tube with coupon and coupon holder

\subsection{Analysis of Tube to End Plug Welds}

Over the three years, a variety of weld tests were conducted to achieve the optimum welding parameters for joining ODS tube to solid end plugs. When the welding parameters or welding schedule developed in 1991 at ANL-W was used in 2008, the resultant microstructure showed that the welding was underpowered and failed to provide adequate bonding. Initially this seemed odd since the welding was so successful in 1991. Further analysis showed that the 1991 materials were a larger size (diameter) but with a smaller wall thickness and exhibited 30\% higher hardness. In essence, the materials were different, resulting in the failed bonds.

An evolution of welding parameters or schedules (a synergism of amperes, cycling times, and pressure) were tried with a variety of results. Welding schedule 20, however, produced an excellent metallurgical bond between the HT-9 end plug and the ODS tubing and 1.5 times thicker bond line. Figure 19 through Figure 23 show an evolution of cracks and the lack of bonding of sample welds. Figure 24 shows the excellent bonding achieved with welding schedule 20 . 


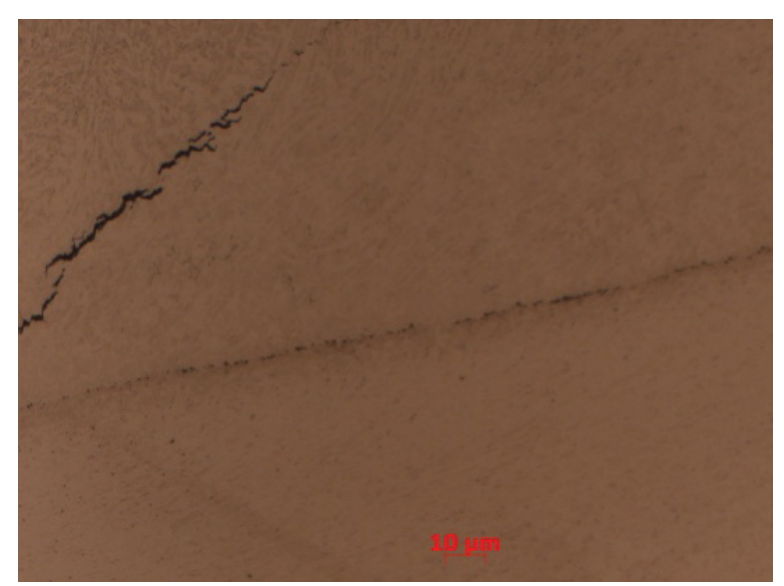

Figure 19. Crack and poor bonding line

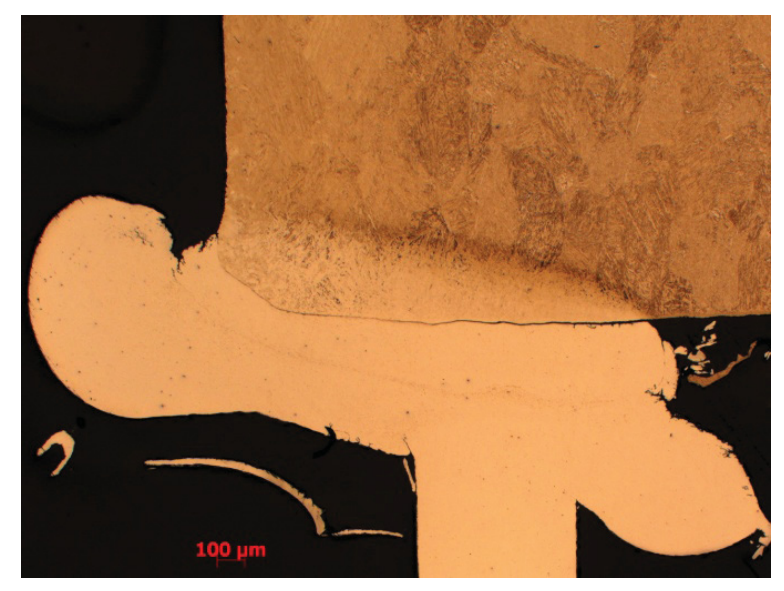

Figure 21. Severe lack of bonding and cracks at interface on both photographs
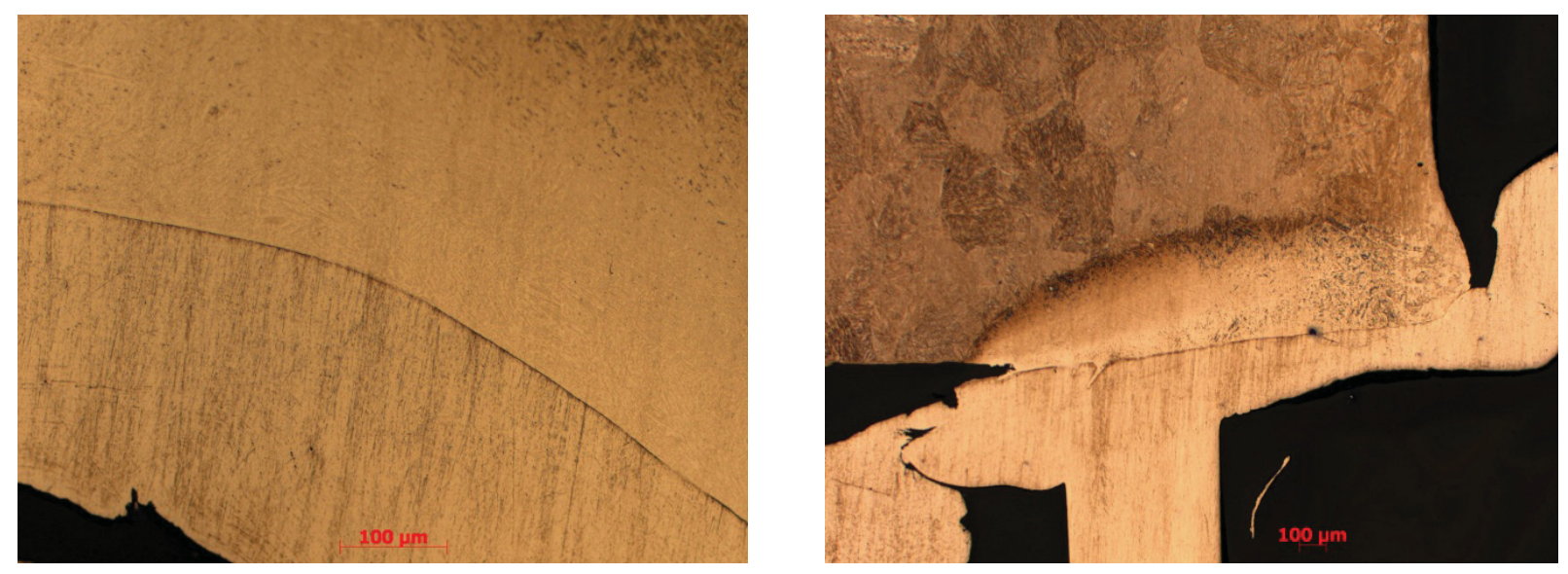

Figure 22. More lack of bonding on both photographs
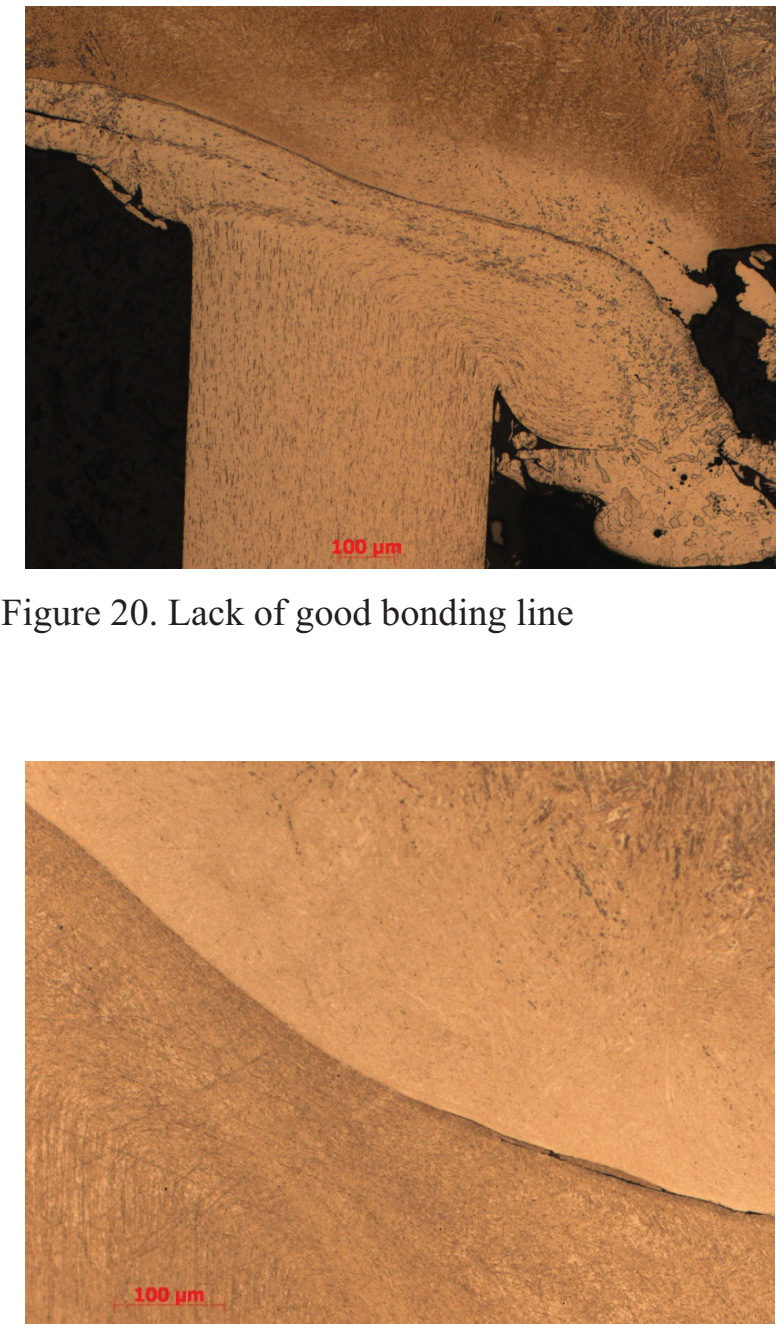

Figure 20. Lack of good bonding line 

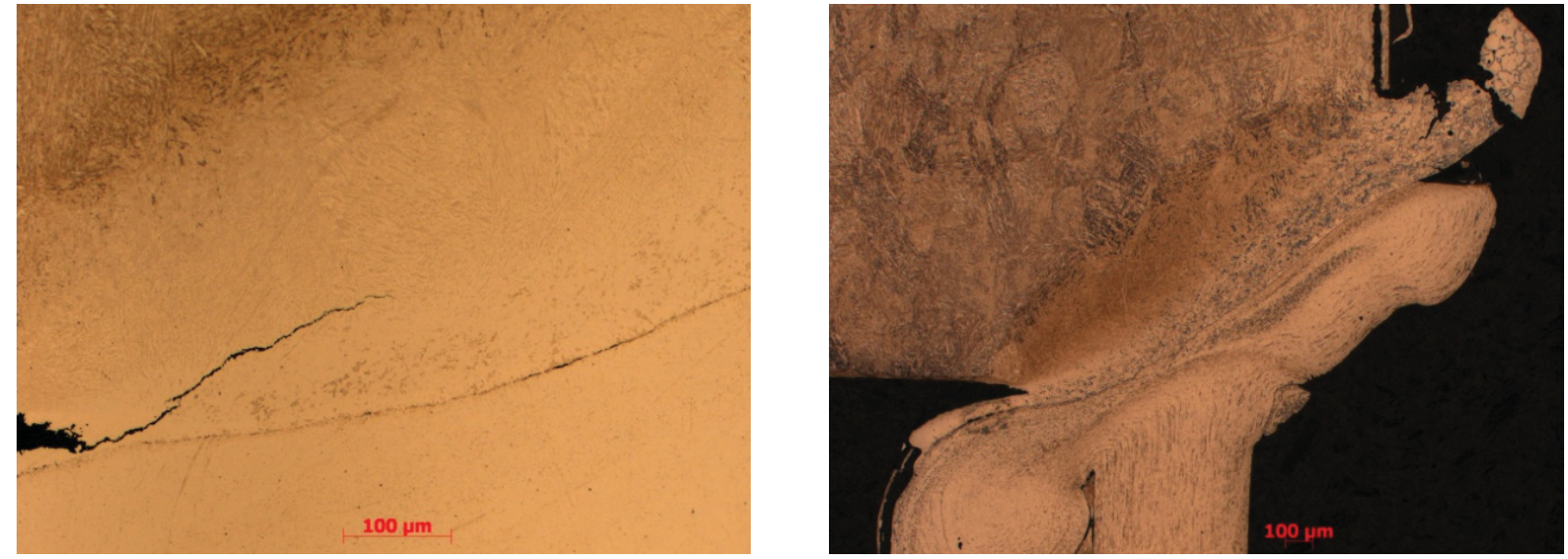

Figure 23. Additional cracking in welds

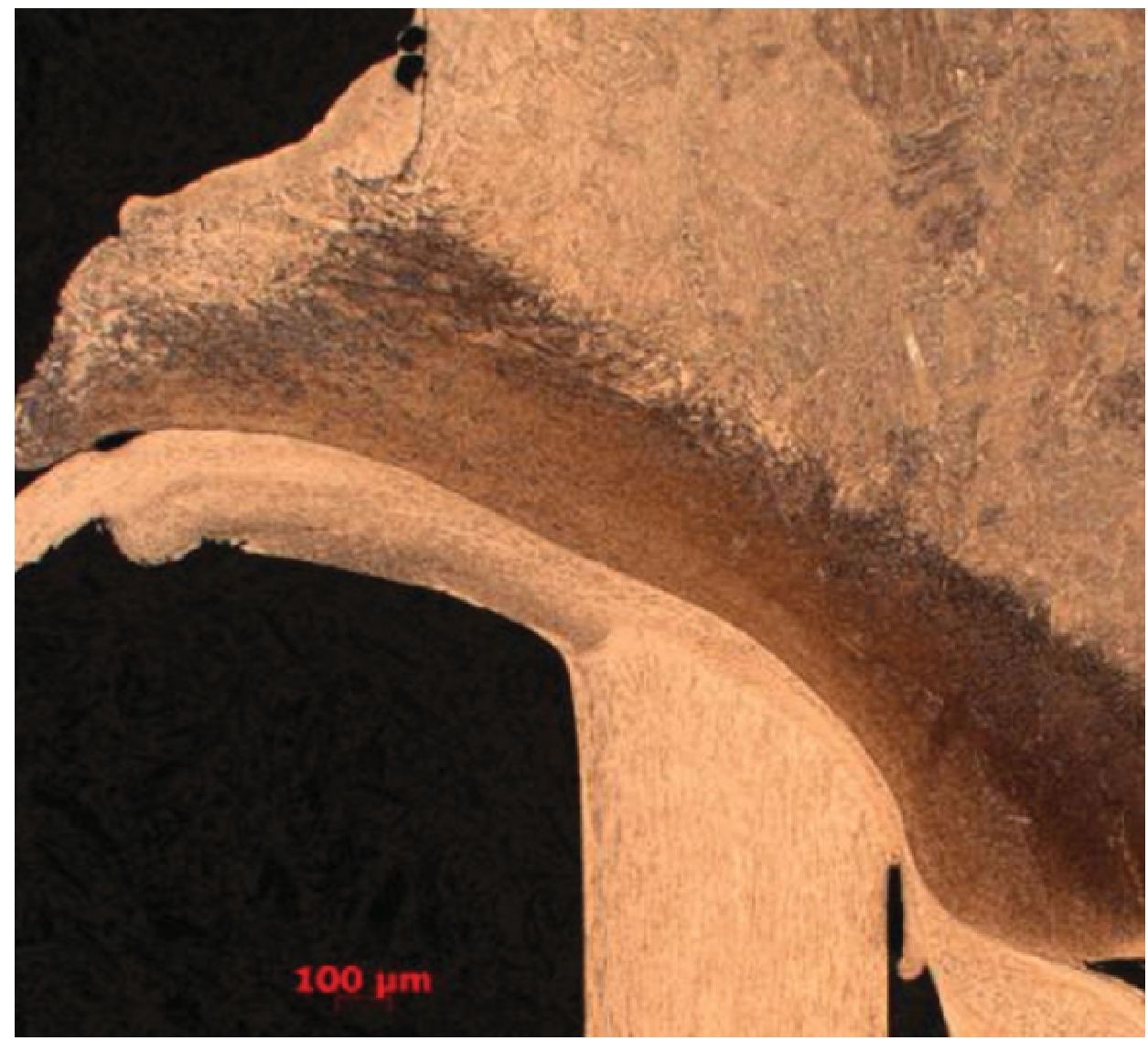

Figure 24. Welding schedule 20 results

Figure 24 is an optical metallography of a bi-metal weld where in the ferritic stainless ODS tubing does not etch (picric acid-based solution) the same as the martensitic stainless steel end plug. To get the ODS ferritic tube to show any etch, the martensitic plug would be over etched. The martensitic structure is evident in the plug as shown by the metallic phase change at the weld line.

The metallurgical bonding is quite evident in the following scanning electron microscope (SEM) images. The boundaries between the two layers or faying surfaces are gone, and the grains show the distinct growth or intertwining of the two materials, typical of a metallurgical bond. Figure 25 through 
Figure 28 shows the images at $200 \mathrm{X}, 500 \mathrm{X}, 1000 \mathrm{X}$, and $5000 \mathrm{X}$ magnifications. An interesting anomaly is seen in the $5000 \mathrm{X}$ image, which shows pitting. The pitting results from the titanium based oxides being ripped from the matrix during the polishing of the ODS material. This is a common anomaly.

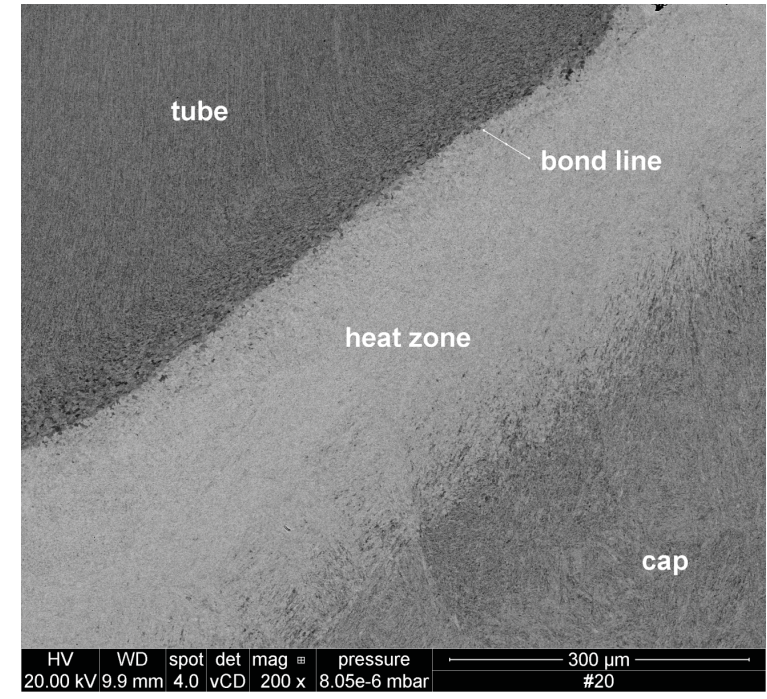

Figure 25. SEM $200 \mathrm{X}$ magnification of bond line.

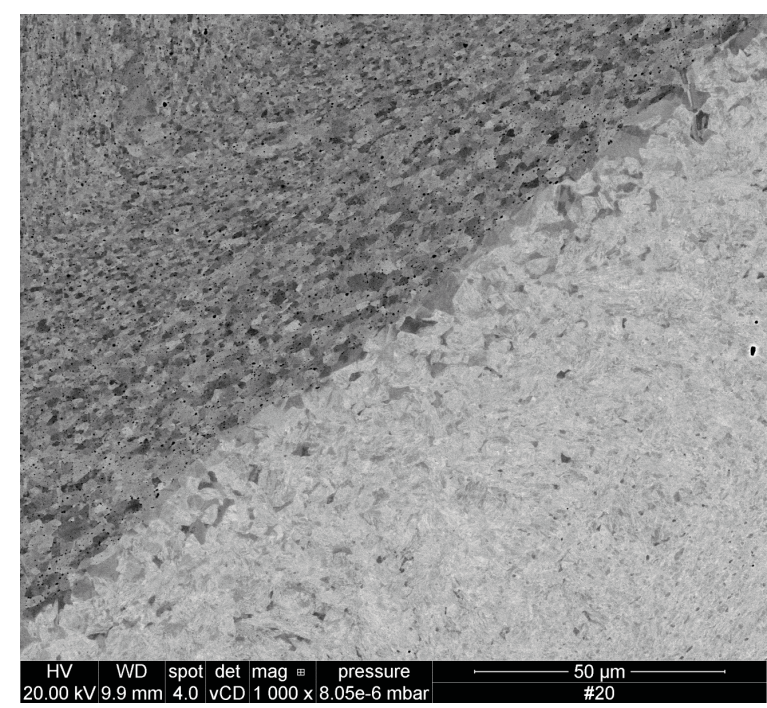

Figure 27. SEM image of bond line at $1000 \mathrm{X}$ Magnification

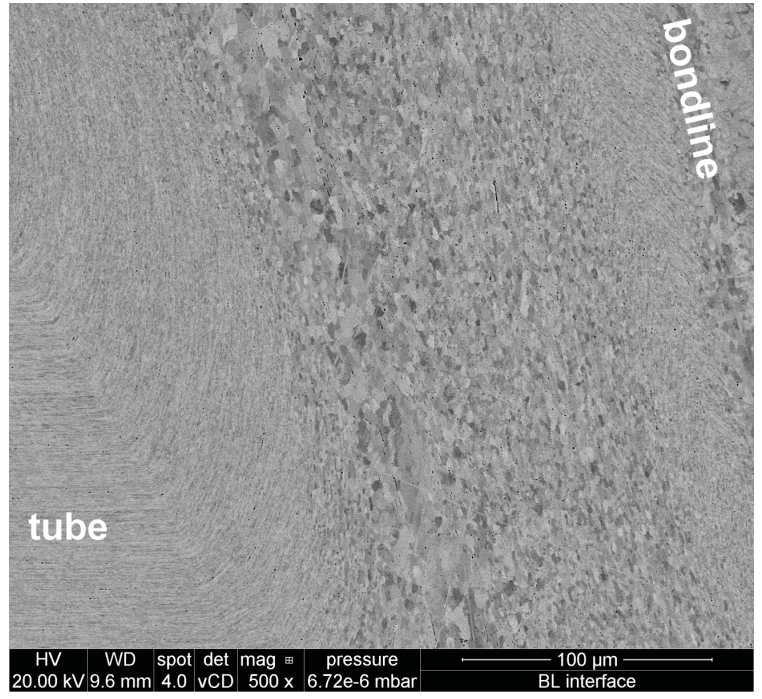

Figure 26. SEM $500 \mathrm{X}$ magnification of bond line

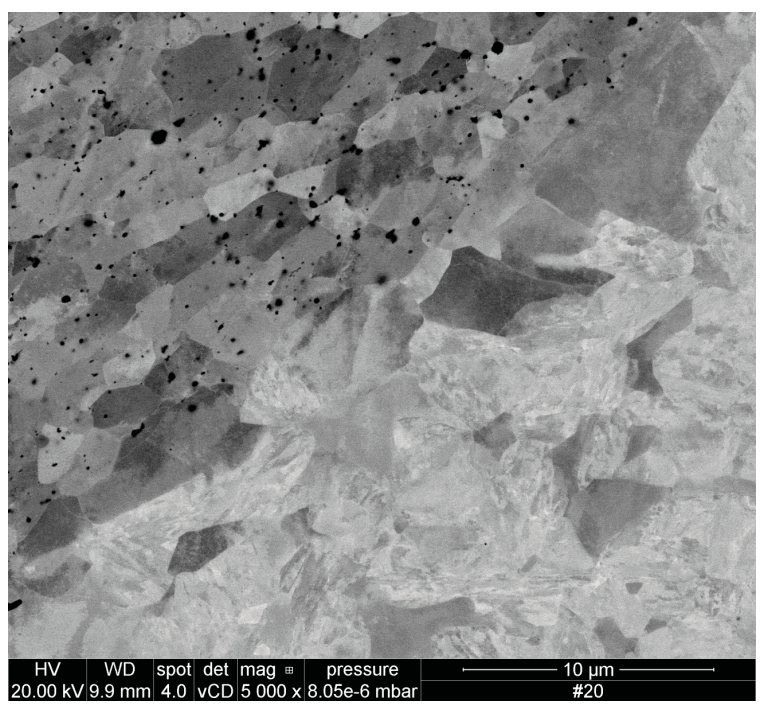

Figure 28. SEM image of bond line at $5000 \mathrm{X}$ magnification.

Other analyses include electron backscatter diffraction (EBSD), energy dispersive x-ray spectroscopy (EDS), and transmission electron microscopy (TEM). The color of the EBSD image in Figure 29 shows the grain orientation. The work hardened tube grains are readily shown to the left of the image. Notice the grains as they are bent during joining ending with some grain growth and recrystalization at the bond line. The grains are becoming re-orientated through the bond region due to the mechanical force being applied through the welding process. The grain re-orientation, as well as deformation, is the result of the mechanical force applied in the welding process. On the far right side of the image the acicular or 
martensitic structure is shown. The TEM images of both the base and weld materials are shown in Appendix H, along with EDS results obtained by the TEM. [More information is detailed in the Master's thesis by the project graduate student, Nathan Jerred.]

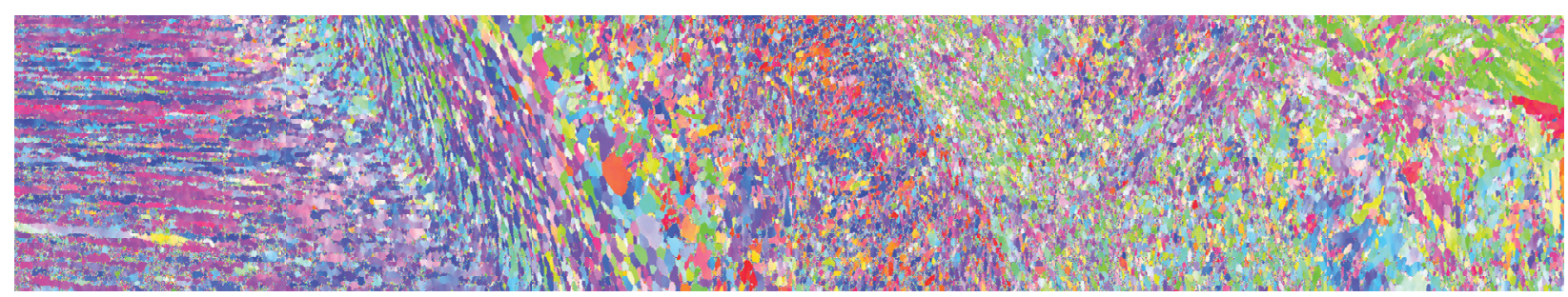

Figure 29. Backscatterer image

\subsection{RW of Non-Tubular ODS Materials to Other Materials}

\subsubsection{Small Piece Welding}

The universities wanted to test the fatigue strength of some small welded samples per the specifications shown in Figure 30. A new small sample welding fixture set was fabricated by Centerline for these tests. Figure 31 shows this fixture with two small pieces touching and before they were welded. The fixture worked fairly well, but the sample had to be machined very precisely to meet the dimension required. Because the universities did not have sufficient funding to machine the small coupon samples, the samples were initially saw-cut. This produced a wide variation of the pieces that rendered many unusable. To join these small pieces, they had to be re-machined for use.

Another problem was the grain direction, a result of hot rolling, of the samples. ODS sheet materials, like tube materials, have a designated grain direction, and it is imperative that samples be welded end grain to end grain to achieve optimal tensile strength. These small samples were saw-cut incorrectly, which caused the side of the grain to be bonded in a manner that is not conducive to achieving correct tensile characteristics. Figure 32 shows examples of the small welded samples before and after tensile testing (i.e., bending). Figure 33 shows the microstructure of the side-bonded welded samples. The bonding is excellent, but would not be sufficient to develop fundamental tensile test data.

S-1 Tensile Specimen

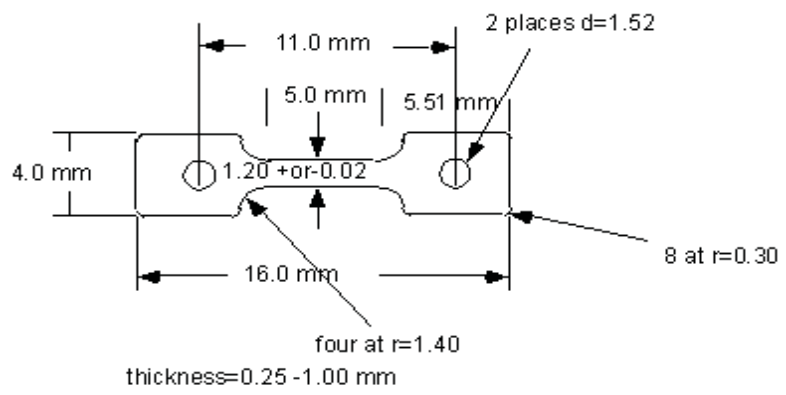

Figure 30. Small sample tensile test

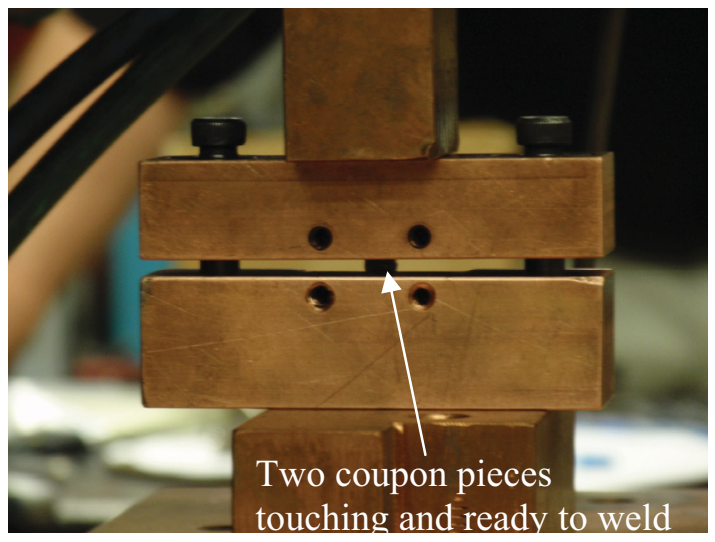

Figure 31. Small sample welding fixture 


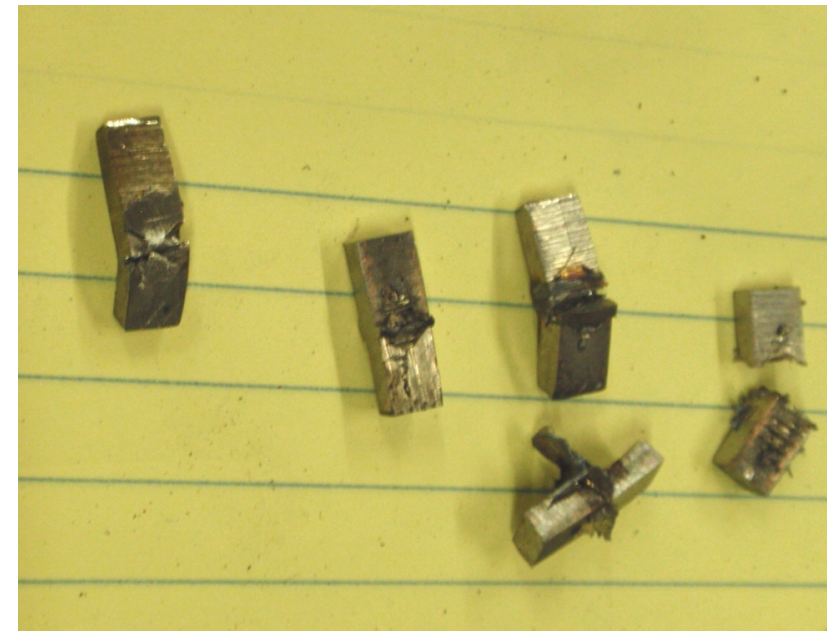

Figure 32. Small pieces before and after bending

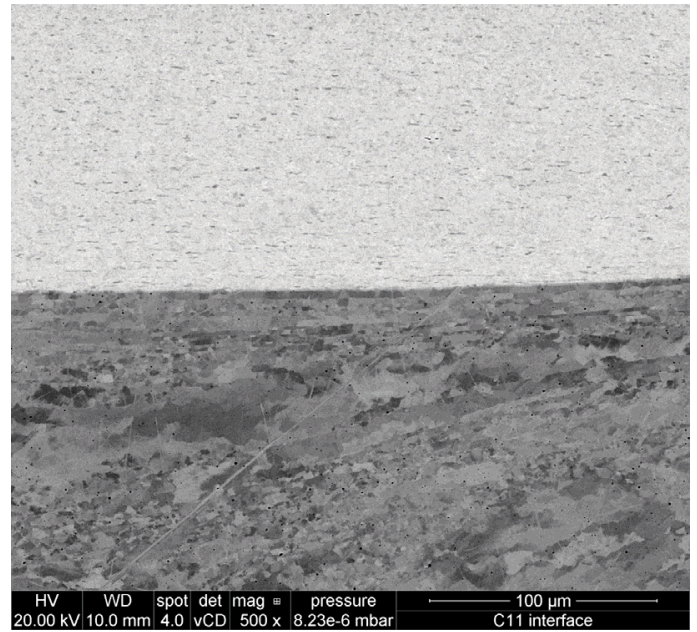

Figure 33. Side-bonded weld (wrong grain direction)

Finally, since the pieces were small and not machined correctly, they could not be aligned correctly. Figure 34 shows bonding, but the pieces were not centered very well. Because of this, some sample were welded but never used as small tensile test samples.

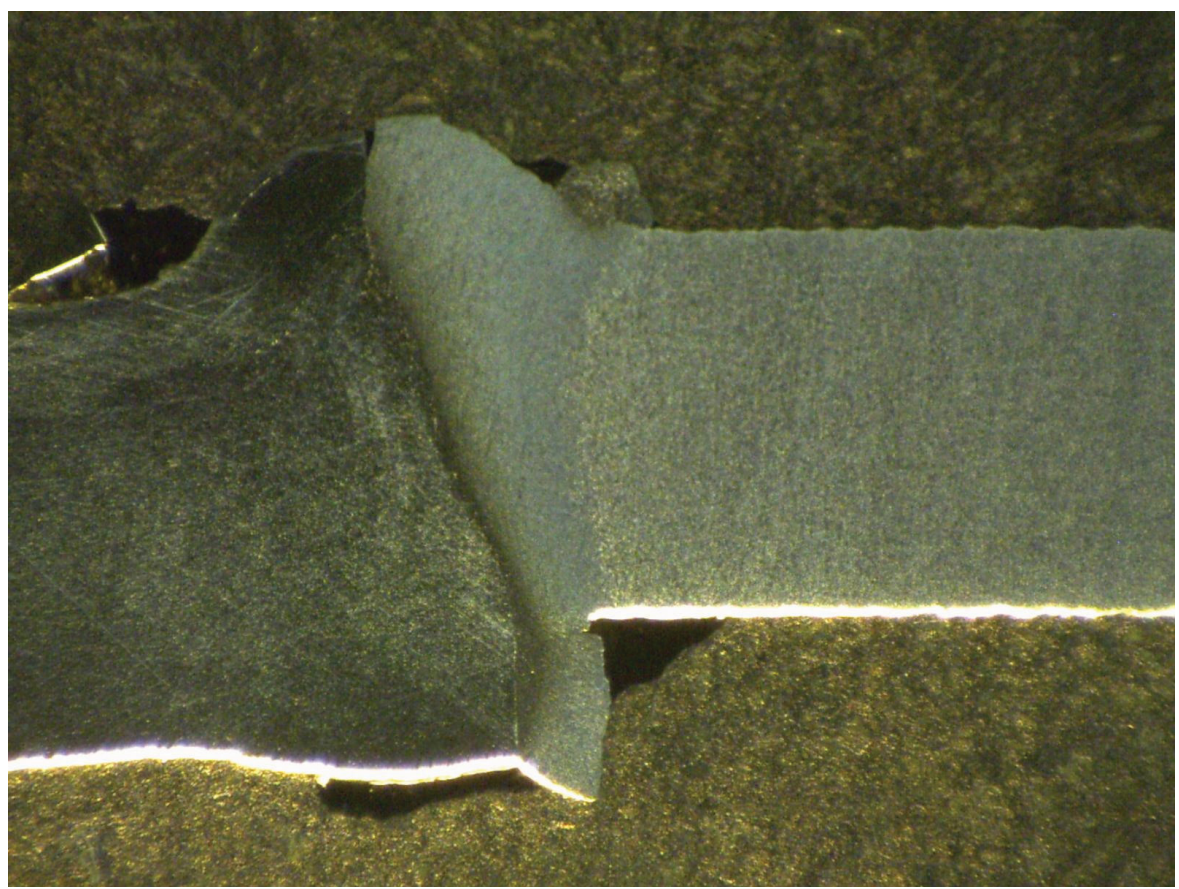

Figure 34. Polished sample but shows misalignment of pieces.

\subsubsection{RW Tungsten to Tungsten Welding}

2010 and 2011 brought increased interest in joining tungsten to tungsten using RW techniques. Pieces of tungsten were machined to the diameter dimension required to fit into the welding fixtures, and the end plug pieces were machined to a length to provide a 0.100 -inch stick out. Although a guess for this alloy, the stick-out length was the same as for the ODS welding. As shown in Figure 35, the tungsten welding fixture uses a two-bolt clam shell (shown on left) to secure the end cap since the piece bottoms out in the 
fixture. The "tube" fixture (shown on right) uses four bolts to hold the smaller diameter tungsten rod in place. During welding, the smaller tube would occasionally slip in the fixture; therefore, a second piece was placed in the fixture to backup the piece being welded. With this backup, no further slippage occurred. The tungsten also off-gased during welding, as shown by the copper staining on the face of the end plug fixture. The tungsten materials required more heat than the ODS materials and, as such, deformed the leading edges of the fixtures and required frequent re-machining of the faces of the two fixtures.

Some interest was also shown in fusion welding of tungsten. Figure 36 shows a gas tungsten arc welded (GTAW) tungsten sample. The welding process actually just melted the larger diameter piece onto the smaller piece without filler metal. The heat was so intense that the sample was red-hot during welding, which completely oxidized the whole sample.

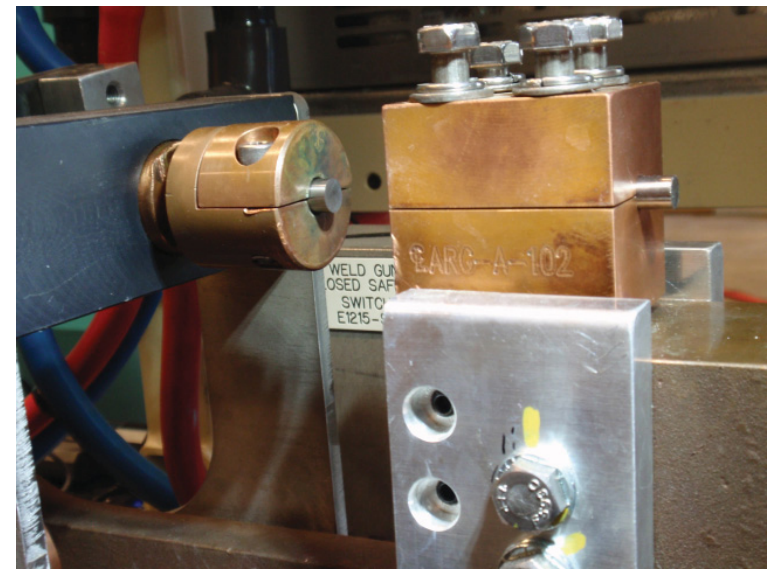

Figure 35. Left fixture with solid back stop

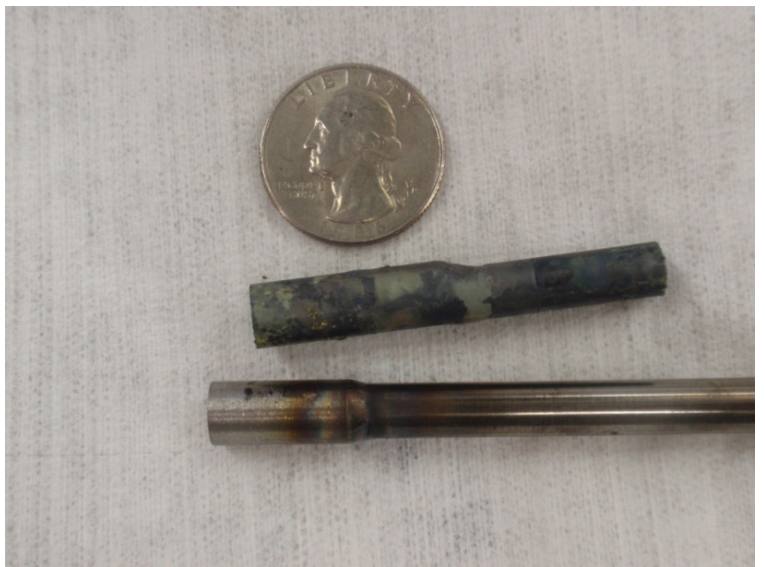

Figure 36. Oxidized tungsten sample (short sample)

\subsubsection{Tungsten to Tungsten Weld Examination}

The first examination of the first tungsten to tungsten weld was a destructive bend test, which failed with minimal force. The third test, however, broke in the base metal and not the weld. Additional samples were welded and given hardness testing, SEM analysis, and EBSD showing crystallographic orientation of the sample grains. Interestingly, the EBSD showed that the two tungsten pieces had different processing or extruding because the base metal grain structure was widely different between the two pieces. Figure 37 shows that the larger diameter piece had coarse grains while the smaller diameter piece had finer grains. The EBSD was conducted with a SEM using an attached EBSD detector. The EBSD image is superimposed over the SEM image. 


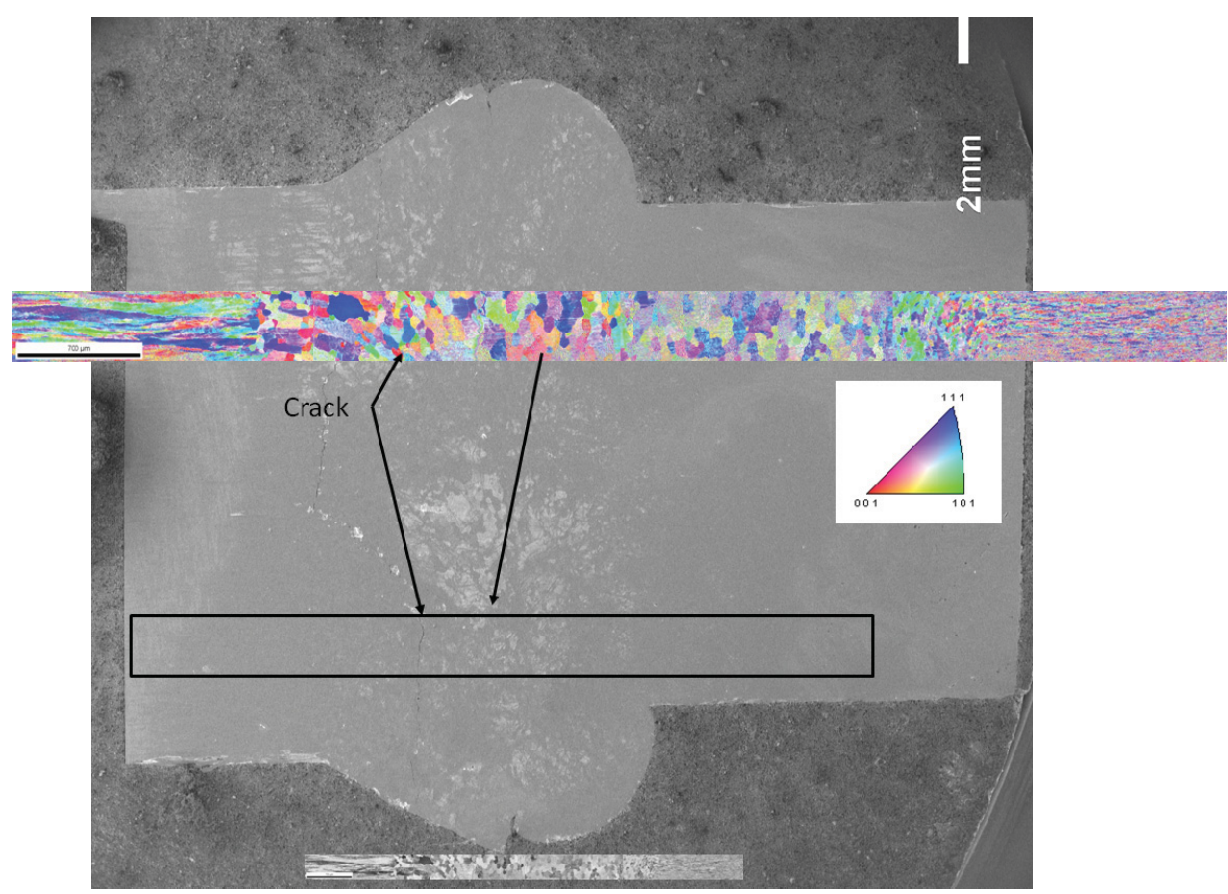

Figure 37. EBSD scan of grain orientation of two tungsten alloys

\section{New Welding Fixtures - 2011}

The 2008 welding fixtures for the RW system were fabricated identical to those of the 1991 system. Eventually, sample number 20 achieved excellent bonding with these fixture, but serious quality issues arose because the fixture design caused uneven heating of the ODS tube to HT-9 end plug welds. Figure 38 shows an example of uneven temper heating marks on the end plug. Figure 39 shows that the amperes during welding would travel more through the bottom half of both fixtures and cause the uneven heating. Figure 40 shows the difference between the weld nugget or size of the heat affected zone between each side of the resulting weld. Under these conditions, artifacts also often occur at the junction between the two halves of the end plug fixture. Such an artifact is shown in Figure 41.

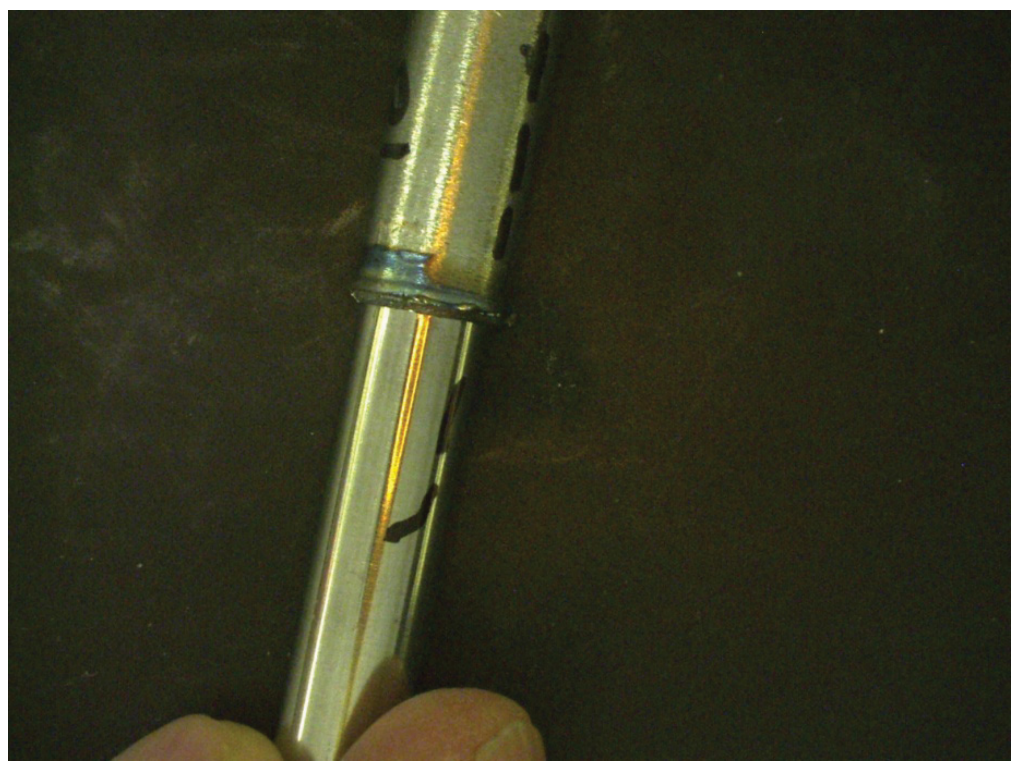

Figure 38. Uneven heating or tempering mark on half of end plug. 


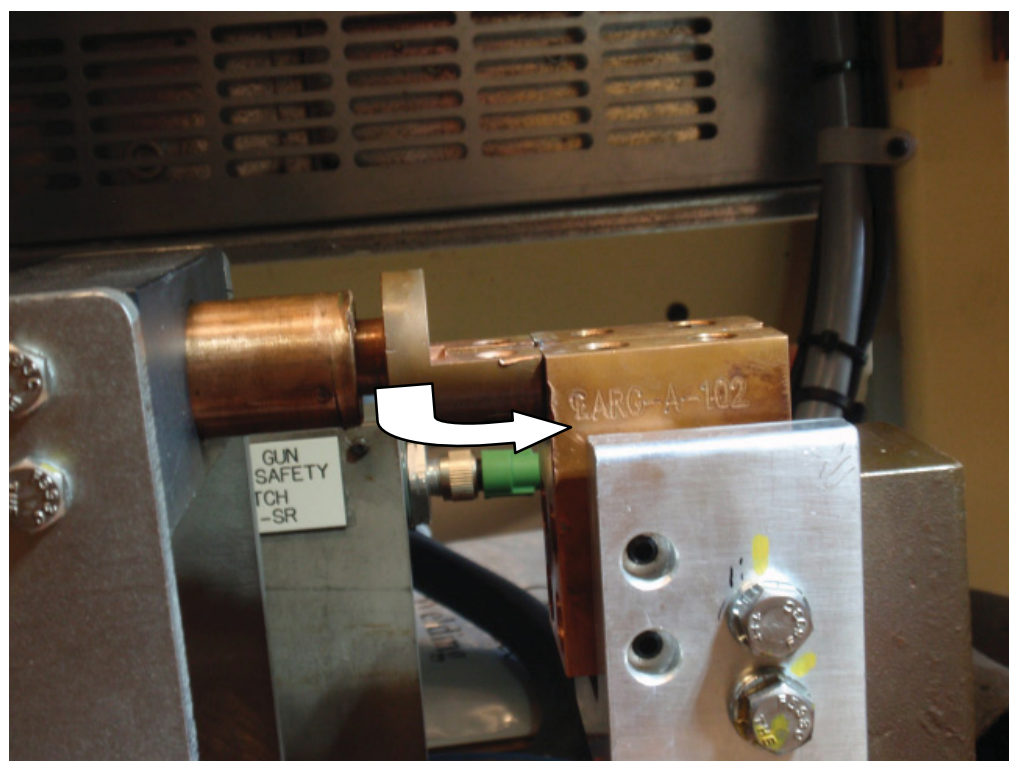

Figure 39. Arrow shows direct path of current — through the bottoms of both fixtures
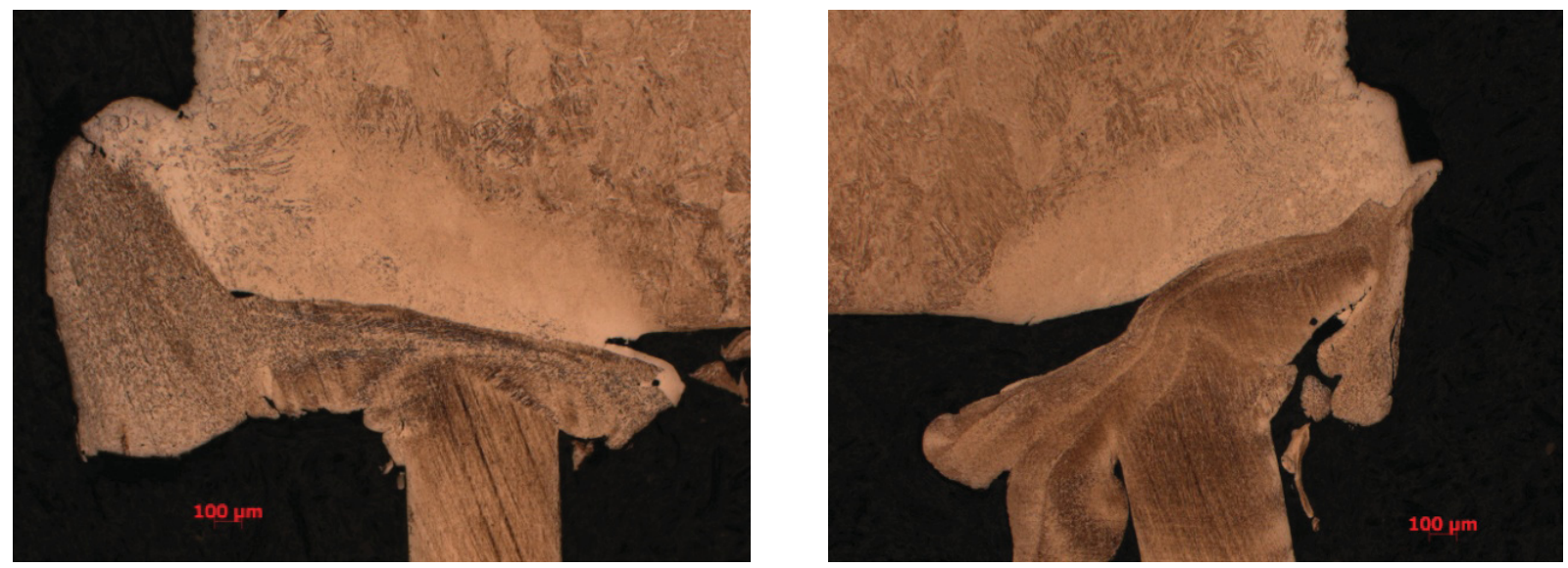

Figure 40. Difference between weld nugget of both sides of the same weld

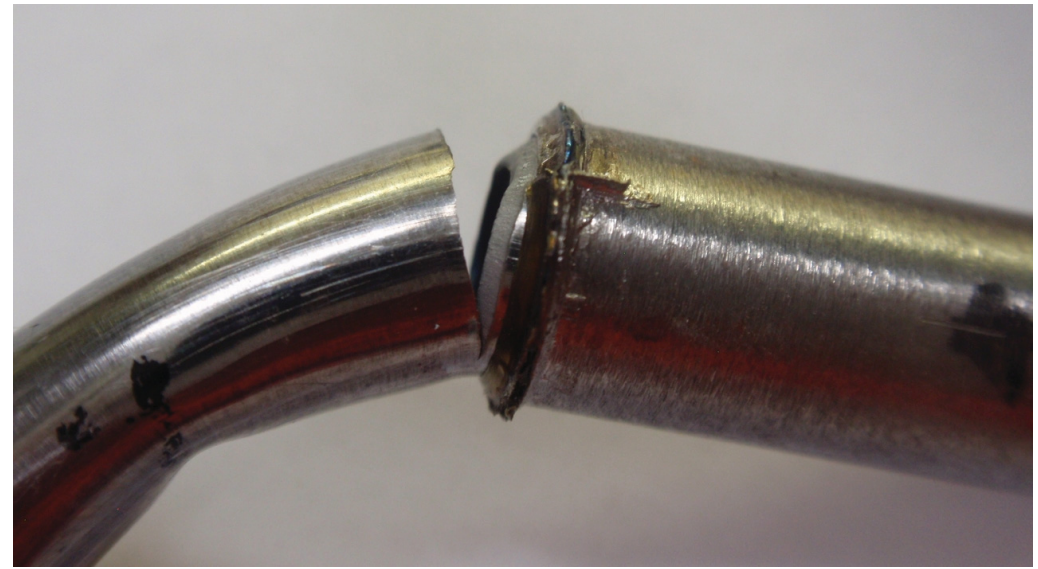

Figure 41. Artifact on end plug 
In 1991, these anomalies did not manifest. Upon analysis, it was discovered that the end plug fixture had an air gap, which reduced the current flow into the top half of the weld. Figure 42 shows an air gap in the fixture. One of the most disheartening events that lead to procuring new fixtures occurred when a professor requested that the CAES welding team fabricate some pressure burst samples. The team set up the systems to produce seven welded samples. The system was energized and a test sample was both welded and given a successful bend test. The seven test coupons were then produced, and another test sample was welded and tested to validate the welding of the samples. This sample failed and subsequently put the quality of the seven welded samples in question (see Figure 43).

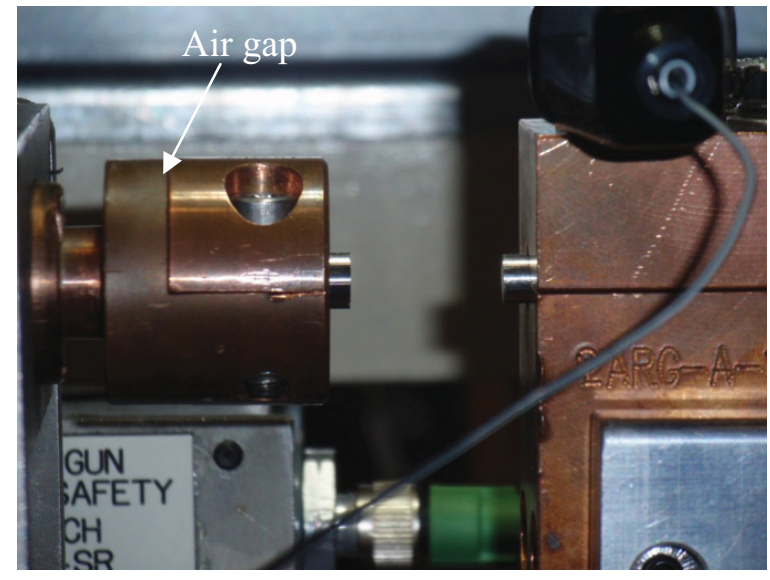

Figure 42. Air gap in fixture

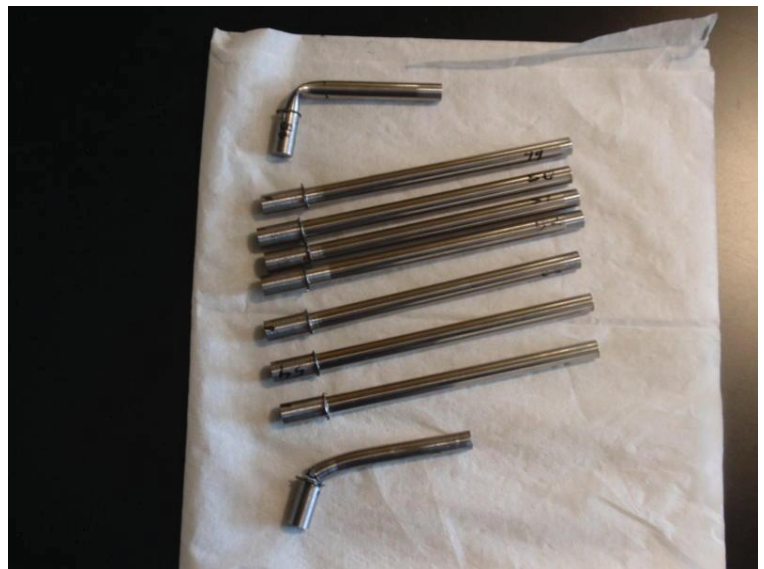

Figure 43. Lack of consistency in welded samples

The CAES welding team consulted the Edison Welding Institute about the problems, whereupon Edison pointed out the ill-designed fixtures and suggest that the system be taken to Columbus, Ohio, to be retrofitted with new fixtures at a prototype machine shop with years of experience in building RW fixtures. The system was shipped to Columbus in August, 2011, and new fixtures were both fabricated and tested. Testing at the machine shop showed that the existing fixtures flexed between 0.003 and 0.006 inches with each weld under the 1000 pound loading. Error! Reference source not found. shows an even heat temper ring on one of the initial welded samples, an unacceptable feature for consistent welds.

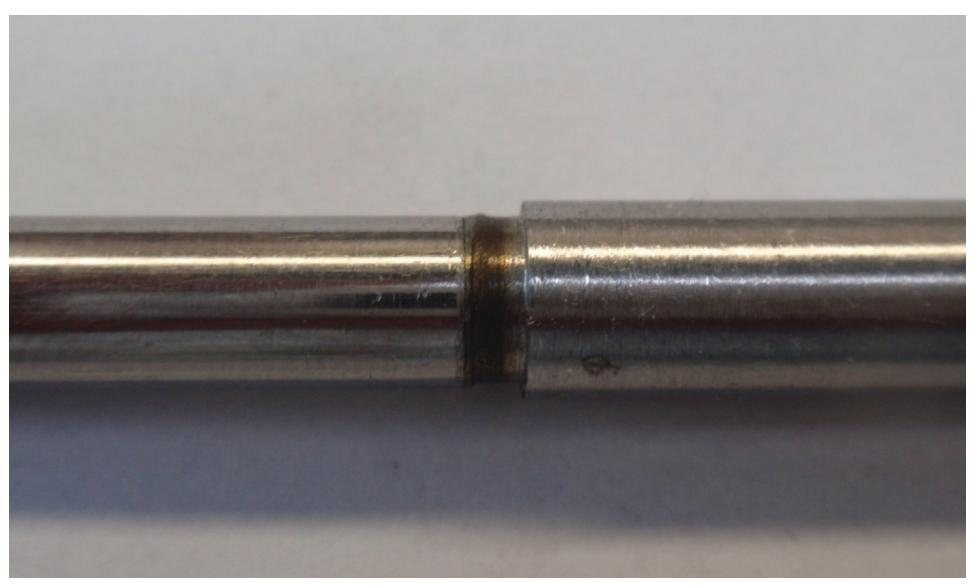

Figure 44. Even temper band on end plug

A new collet type fixture was proposed to correct the problem. Figure 45 shows the old clamshell fixtures, while Figure 46 shows the first version of a collet type fixtures with a stiffening bracket. 


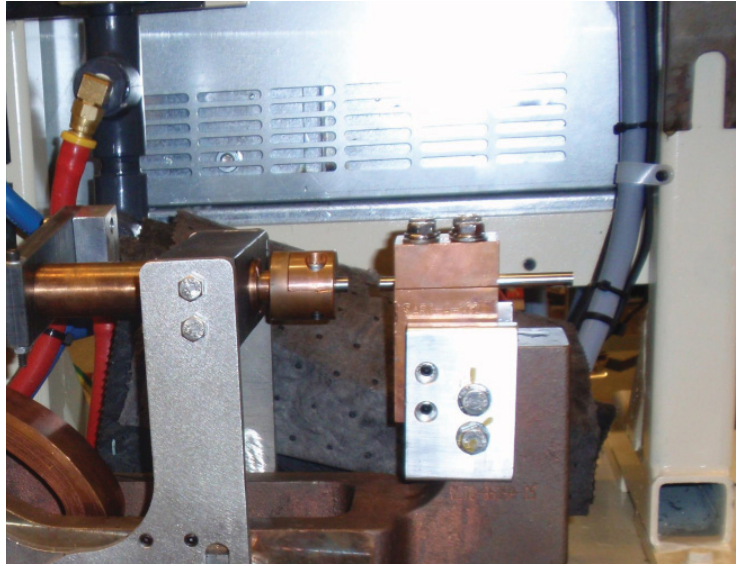

Figure 45. Old clamshell electrodes tooling

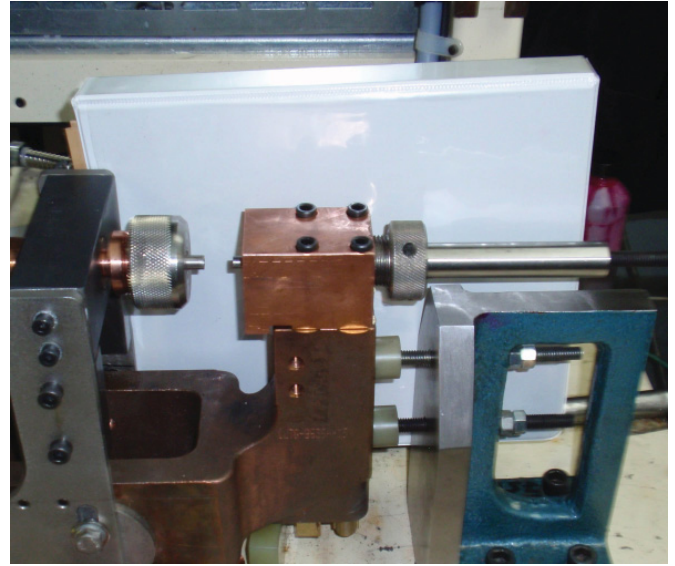

Figure 46. Collet electrode tooling with stiffener

The collet fixture was a great improvement in providing an even temper band around the end plug material. After a few days of welding, changes were made to the fixtures' internal parts and new fixtures were then fabricated. No photographs of these newer fixtures are shown at this time. Appendix J shows the work order for obtaining the new fixtures.

\section{Conclusions}

The CAES welding team achieved the following:

- Successfully joined ODS tubing to a solid end plug and achieved an excellent metallurgical bond

- Joined smaller size samples, but due to the cutting direction of the machining, the samples were essentially lost for testing

- Successfully joined tungsten alloys using resistance welding

- Obtained excellent metallurgical analysis with a variety of electronic microscopes: SEM, TEM, EBSD, and EDS

- Developed a new set of welding fixtures in 2011 for future welding

- Searched for solutions to other welding joints or configurations and discovered a 1970's example of RW of Russian zirconium fuel elements. Initial tests were conducted in Ohio and the results look promising for future consideration or use of the Russian techniques.

- Interfaced with the Edison Welding Institute scientists, who suggested a few alternative joint designs and techniques for future consideration.

For future work, materials must be developed or purchased, because the remaining INL stock is limited. The CAES RW system and tooling is currently ready for subsequent welding development tests.

\section{Publishing Findings}

The CAES welding team presented papers at four conferences and one poster session. Figure 47 shows Nathan Jerred presenting his poster at the Idaho Space Grant Consortium Graduate Student Poster Session. The titles of the published papers are listed in Appendix I. 


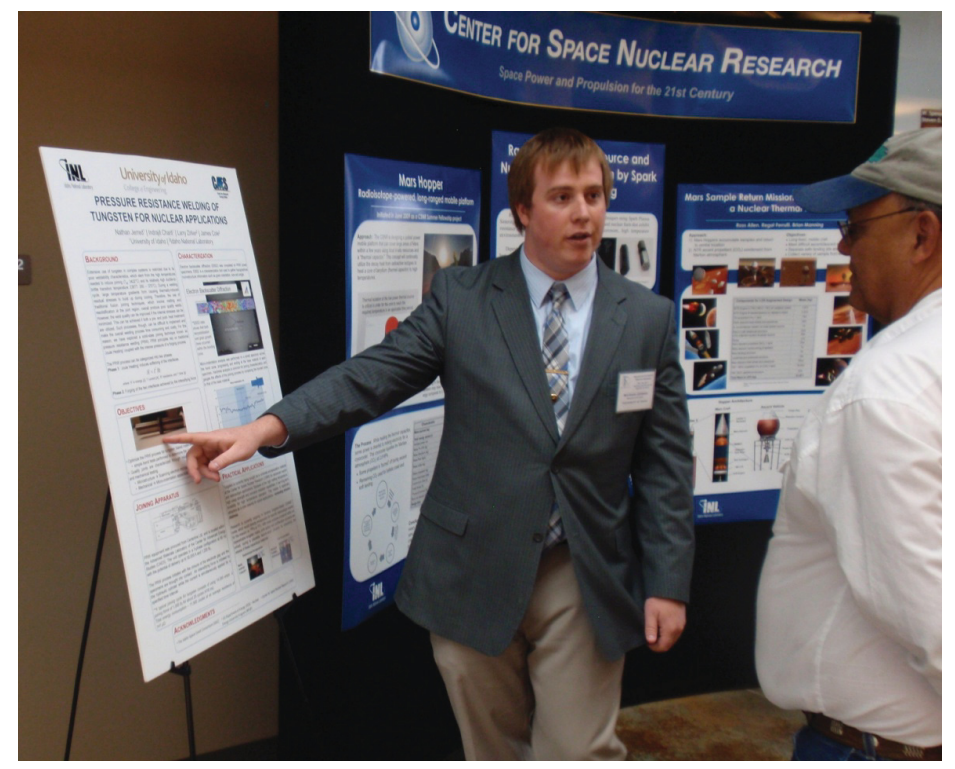

Figure 47. Nathan Jerred at the Idaho Space Grant Consortium Graduate Student Poster Session in 2010 